\title{
Dynamic modeling of nitrogen losses in river networks unravels the coupled effects of hydrological and biogeochemical processes
}

\author{
Richard B. Alexander · John Karl Böhlke · Elizabeth W. Boyer • \\ Mark B. David · Judson W. Harvey · Patrick J. Mulholland · Sybil P. Seitzinger • \\ Craig R. Tobias $\cdot$ Christina Tonitto $\cdot$ Wilfred M. Wollheim
}

Received: 1 May 2008/Accepted: 21 September 2008/Published online: 7 January 2009

(C) The Author(s) 2008. This article is published with open access at Springerlink.com

\begin{abstract}
The importance of lotic systems as sinks for nitrogen inputs is well recognized. A fraction of nitrogen in streamflow is removed to the atmosphere via denitrification with the remainder exported in streamflow as nitrogen loads. At the watershed scale, there is a keen interest in understanding the factors that control the fate of nitrogen throughout the stream
\end{abstract}

R. B. Alexander $(\varangle) \cdot$ J. K. Böhlke · J. W. Harvey U.S. Geological Survey, 12201 Sunrise Valley Drive, Reston, VA 20192, USA

e-mail: ralex@usgs.gov

E. W. Boyer

Pennsylvania State University, University Park,

PA 16802, USA

M. B. David

University of Illinois, Urbana, IL 61801, USA

P. J. Mulholland

Oak Ridge National Laboratory, Oak Ridge, TN 37831, USA

S. P. Seitzinger

Rutgers University, New Brunswick, NJ 08901, USA

C. R. Tobias

University of North Carolina, Wilmington, NC 28403, USA

C. Tonitto

Cornell University, Ithaca, NY 14853, USA

W. M. Wollheim

University of New Hampshire, Durham, NH 03824, USA channel network, with particular attention to the processes that deliver large nitrogen loads to sensitive coastal ecosystems. We use a dynamic stream transport model to assess biogeochemical (nitrate loadings, concentration, temperature) and hydrological (discharge, depth, velocity) effects on reach-scale denitrification and nitrate removal in the river networks of two watersheds having widely differing levels of nitrate enrichment but nearly identical discharges. Stream denitrification is estimated by regression as a nonlinear function of nitrate concentration, streamflow, and temperature, using more than 300 published measurements from a variety of US streams. These relations are used in the stream transport model to characterize nitrate dynamics related to denitrification at a monthly time scale in the stream reaches of the two watersheds. Results indicate that the nitrate removal efficiency of streams, as measured by the percentage of the stream nitrate flux removed via denitrification per unit length of channel, is appreciably reduced during months with high discharge and nitrate flux and increases during months of low-discharge and flux. Biogeochemical factors, including land use, nitrate inputs, and stream concentrations, are a major control on reach-scale denitrification, evidenced by the disproportionately lower nitrate removal efficiency in streams of the highly nitrate-enriched watershed as compared with that in similarly sized streams in the less nitrate-enriched watershed. Sensitivity analyses reveal that these important biogeochemical factors and physical hydrological factors contribute nearly equally 
to seasonal and stream-size related variations in the percentage of the stream nitrate flux removed in each watershed.

Keywords Denitrification - Seasonal · Nitrate model · LINX · NHD river network · Nitrate loss - Nitrate removal efficiency · Anthropogenic nitrogen

\section{Introduction}

Recent progress in the measurement and modeling of denitrification in lotic ecosystems includes reachscale measurements that account for hyporheic effects (e.g., Böhlke et al. 2004; Mulholland et al. 2004, 2008) and empirical and mechanistic models of aquatic denitrification that quantify nitrogen removal over watershed scales (Boyer et al. 2006). These studies highlight the importance of both hydrological and biogeochemical factors that control denitrification. Hydrological discharge regimes affect the degree of interaction of the water column (and its nutrient load) with the hyporheic streambed sediments; rates of nutrient removal via denitrification are typically higher under low versus high-discharge conditions, related to the effects of water depth and velocity. Biogeochemical cycles in aquatic ecosystems affect (and are affected by) conditions in the water column and streambed, including stream temperature, the supply of biogenic nutrients (e.g., nitrate, organic carbon, dissolved oxygen), respiration rates, and stream temperature, which all influence the magnitudes and rates of denitrification (Boyer et al. 2006). Although much has been learned about the principal controls on denitrification from process studies in individual reaches and catchments (PinaOchoa and Alvarez-Cobelas 2006; Birgand et al. 2007), the effects of denitrification on nitrogen removal in river networks at regional scales have been primarily inferred from empirical relations that correlate the rates of nutrient removal with mean annual discharge and related hydraulic measures for streams and lakes (e.g., water velocity, depth, time of travel; Howarth et al. 1996; Alexander et al. 2000, 2008; Donner et al. 2002; ; Seitzinger et al. 2002; Boyer et al. 2006; Wollheim et al. 2006, 2008a). These hydrological properties are generally well correlated with the measures of denitrification reported in the literature, explain considerable spatial variation in aquatic nitrogen removal, and are readily generalized for large river networks from geospatial data.

By contrast, much less has been reported about how denitrification affects nitrogen removal within river networks in response to inter-annual and seasonal variability in denitrification, water-column nutrient concentrations and loads, and hydrological discharge regime. One difficulty is that stream denitrification is most commonly measured during the warmer months of the year and typically during low to moderate discharge conditions that are necessary to ensure the accuracy of tracer studies. Little is known about nitrogen removal during periods of high discharge, when much (and typically most) of the riverine nitrogen load is transported from watersheds and delivered to coastal waters, where reactive nitrogen has contributed to the degradation of estuarine ecosystems. Nutrient spiraling concepts and first-order kinetics suggest that the fraction of nitrogen removed in streams (i.e., $1-e^{-k t}$ ) would be expected to decrease during high-discharge periods because of reduced water contact time in reaches, related to a decline in both the volume-dependent reaction rate constant $(k)$ and water residence time $(t)$. The few studies of seasonal variability in discharge and nitrate flux in relation to seasonal rates of denitrification (Royer et al. 2004; Smith et al. 2006; Böhlke et al. 2008) indicate that the removal of stream nitrate mass by denitrification in Midwestern streams is relatively inefficient during highdischarge, spring periods of the year because of the relatively high nitrate concentrations and loads as well as high water velocities (and low solute residence times). Other studies (Garcia Ruiz et al. 1998; Mulholland et al. 2008) also report the mediating effects of nitrate concentrations and loads on stream nitrate removal by denitrification. However, few attempts have been made to unravel the coupled effects of biogeochemical (nitrate loadings, concentration, temperature) and hydrological (discharge, depth, velocity) factors on in-stream nitrogen removal over space and time within river networks (Wollheim et al. 2008b). These evaluations are needed to improve understanding of the separate effects of anthropogenic nitrogen sources and natural hydrological variability on denitrification and nitrogen transport over a wide range of spatial and 
temporal scales, especially those relevant to the coastal delivery of nitrogen.

Here, we use a dynamic stream transport model to simulate denitrification-induced nitrate removal (i.e., nitrate losses) in the river networks of two case study watersheds with highly contrasting levels of nitrate enrichment (loadings and concentrations) and similar discharge and hydraulic conditions. Unique to our model is the use of more than 300 published field measurements (Royer et al. 2004; Opdyke et al. 2006; Smith et al. 2006; Opdyke and David 2007; Böhlke et al. 2008; Mulholland et al. 2008, 2009) to estimate the dependence of stream denitrification on nitrate concentration, temperature, and hydrological properties (discharge, water velocity, and depth). The field data are available for a diverse set of US streams, and include observations reported over time for selected sites. A systematic comparison of these denitrification data, as provided in this study, has not been previously presented in the literature. We apply the stream transport model to the first- through fourthorder stream reaches of the two watersheds, using their 1:100,000 scale river networks (enhanced version of the national hydrography dataset, USGS 2000) and records of monthly discharge and nitrate loadings spanning a 7-20 year period. In view of the similar range of discharge and hydraulic properties in the watersheds, differences between the watersheds in the model predictions of nitrate removal primarily reveal the impacts of nitrate enrichment, related to the biogeochemical effects of nitrate loadings and stream concentrations. Sensitivity evaluations of the transport model are used to further separate biogeochemical effects of nitrate enrichment from hydrological effects (discharge, velocity, depth) on temporal and spatial variability in stream nitrate removal within the watersheds.

\section{Methods: estimating stream nitrate transport}

We constructed a dynamic transport model to simulate monthly nitrate flux and in-stream removal by denitrification for the river networks of the two case study watersheds. The model simulations are illustrative of the potential effects of denitrification on instream nitrate removal and are not intended to reproduce the actual in-stream nitrate flux that occurs in these watersheds. In the first section of this paper, we describe the conceptual and mathematical framework of the transport model used to evaluate denitrification effects on nitrate flux and in-stream removal. In the second section, we provide background on the two case study watersheds. The third section presents the published field measurements of stream denitrification and the regression equations that are used to estimate denitrification as a function of key rate-controlling variables and simulate nitrate dynamics in the transport model. In a final section, we describe the methods for applying the transport model to the river networks of the two watersheds.

\section{The dynamic nitrate transport model}

Our model of in-stream nitrate transport is based on a one-dimensional version of the advection-dispersion equation (e.g., Stream Solute Workshop 1990) that includes non-conservative transport and assumes negligible effects from solute mixing related to dispersion and transient storage. We model nitrate transport within a reach segment $i$ as a steady-state process within each month $s$ under the assumption that discharge $\left(Q_{i, s}\right)$ and cross-sectional area $\left(A_{i, s}\right)$ are constant during each month. Thus, the nitrate flux $\left(F_{i, s}^{D}\right.$; mass per unit time) at the downstream portion of reach $i$ can be expressed as the sum of two components: the decayed nitrate fluxes from one or more adjacent upstream reaches, denoted by $j$, and the decayed lateral nitrate loadings from the incremental drainage of reach $i$, described according to

$F_{i, s}^{D}=F_{j, s} e^{\frac{-k_{i, s} A_{i, s} x_{i}}{Q_{i, s}}}+F_{i, s}^{I} e^{\frac{-k_{i, s} A_{i, s} 0.5 x_{i}}{Q_{i . s}}}$

where $F_{j, s}$ is the stream nitrate flux exported from the upstream reach, $k$ is the volumetric-related, first-order reaction rate constant (units of time ${ }^{-1}$ ), $x_{i}$ is the reach length; and, $F_{i, s}^{I}$ is the lateral input of nitrate flux in surface and subsurface inflows from the incremental drainage, subjected to one half of the water travel time associated with the reach (in reality, the lateral loadings are introduced along the entire stream reach, which is simplified in the reach segmentation of the model by assuming that the nitrate inputs travel, on average, one half the length of the reach). Note that $\frac{Q_{i, s}}{A_{i, s}}$ is the mean water velocity, $v_{i, s}$ (units of length time ${ }^{-1}$ ) and the mean solute residence time, $t_{i, s}$ is expressed as $\frac{A_{i, s} x_{i}}{Q_{i, s}}$. Note also that the original advective-dispersion equation is described in terms of 
concentration and discharge, which is alternatively expressed as flux in Eq. 1.

Equation (1) gives the steady-state solution to the advection-dispersion equation, which has been commonly employed in nutrient spiraling studies over short time scales (e.g., Newbold et al. 1981) and in large-scale watershed mass balance studies over long time scales (e.g., Donner et al. 2002; Alexander et al. 2008). Assuming that the reaction rate constant is first-order, this rate may be expressed as a function of the benthic areal denitrification rate $\left(U_{i, s}\right)$ and the water-column nitrate concentration $\left(C_{i, s}\right)$, such that

$k_{i, s}=\frac{U_{i, s}}{C_{i, s} d_{i, s}}=\frac{V_{i, s}^{f}}{d_{i, s}}$

where $V_{f}$ is a mass-transfer rate coefficient (i.e., apparent "settling" velocity or uptake velocity; units $=$ length time $_{-1}$ ) and $d$ is the water depth. Conceptually, the mass-transfer rate is the vertical velocity at which nitrate mass migrates from the water column to the benthic sediment and is removed via denitrification. Under the assumptions associated with Eq. 2, the mass-transfer coefficient has been frequently cited as a measure of biological differences in nitrogen removal among experimental sites because the measure is mathematically independent of hydrologic-related properties, such as water depth (Wollheim et al. 2006). Note, however, that this independence does not hold if the assumptions of steady-state conditions and negligible dispersion and transient storage are relaxed (e.g., Runkel 2007).

The first-order assumptions associated with Eq. 2 stipulate that the areal denitrification rate and concentration are linearly related to one another according to a proportionality constant as specified by the mass-transfer rate. However, nonlinear relations have been recently observed between the areal denitrification rate (and mass-transfer rate) and water-column nitrate concentration for a variety of stream environments, based on the field data examined in this study (Mulholland et al. 2008, 2009; Böhlke et al. 2008). Therefore, as described below, we estimate regression-based expressions of the reaction rate constant $k$ and benthic areal rate $U$ as a nonlinear function of nitrate concentration and depth (or discharge), which are then used to simulate nitrate removal in the stream transport model.
Case study watersheds for applying the nitrate transport model

We apply the nitrate transport model (Eq. 1) to streams in the $466-\mathrm{km}^{2}$ Sugar Creek watershed in Indiana and Illinois (upper Mississippi River Basin) and those in a somewhat smaller watershed $\left(282 \mathrm{~km}^{2}\right)$, that of the North Nashua River (hereafter referenced as the Nashua River) in MA, a subwatershed of the Merrimack River (see Fig. 1). Measures of stream hydrology in both watersheds (i.e., discharge, water depth, and water velocity) display a generally similar range of variability (e.g., median discharge ranges from 0.01 to $10 \mathrm{~m}^{3} \mathrm{~s}^{-1}$ ), whereas the highly contrasting levels of nitrate enrichment (nitrate loadings and stream concentrations) of the two watersheds reflect large differences in land use and population density (e.g., median predicted nitrate concentrations range from 60 to 1,000 and $<20 \mu \mathrm{mol} \mathrm{N}{ }^{-1}$ for Sugar Creek and the Nashua River, respectively). The Sugar Creek watershed is predominantly agricultural fields with row crops covering more than $90 \%$ of the drainage area, whereas the Nashua watershed is predominantly forested $(\sim 60 \%)$, with a relatively high population density in moderately urbanized areas $(\sim 20 \%$ of the drainage area). Agricultural fields in the Sugar Creek watershed are artificially drained (i.e., tile drainage), and many headwater streams have been channelized (i.e., deepened and straightened). Stream topology is defined for the catchments of these watersheds according to the 1:100,000-scale national hydrography data (NHD) river network (USGS 2000), which includes 104 stream reaches in Sugar Creek watershed and 174 reaches in the Nashua River watershed; the reaches are defined as segments extending between tributary junctions. Comparisons of the Horton-Strahler stream classification for NHD with that for more finely resolved 1:24,000-scale streams (e.g., Andrews et al. 2002) suggest that NHD headwater streams would be generally classified as second-order streams at the finer scale, and may include many streams with intermittent discharge. Note that the Nashua River network contains nearly 25 lakes; we modeled these as streams using the thalweg NHD trace reaches and their associated reach properties (e.g., discharge, depth) in the model simulations. 
Fig. 1 Locations of the case study watersheds, Sugar Creek, Illinois and the North Nashua River, MA

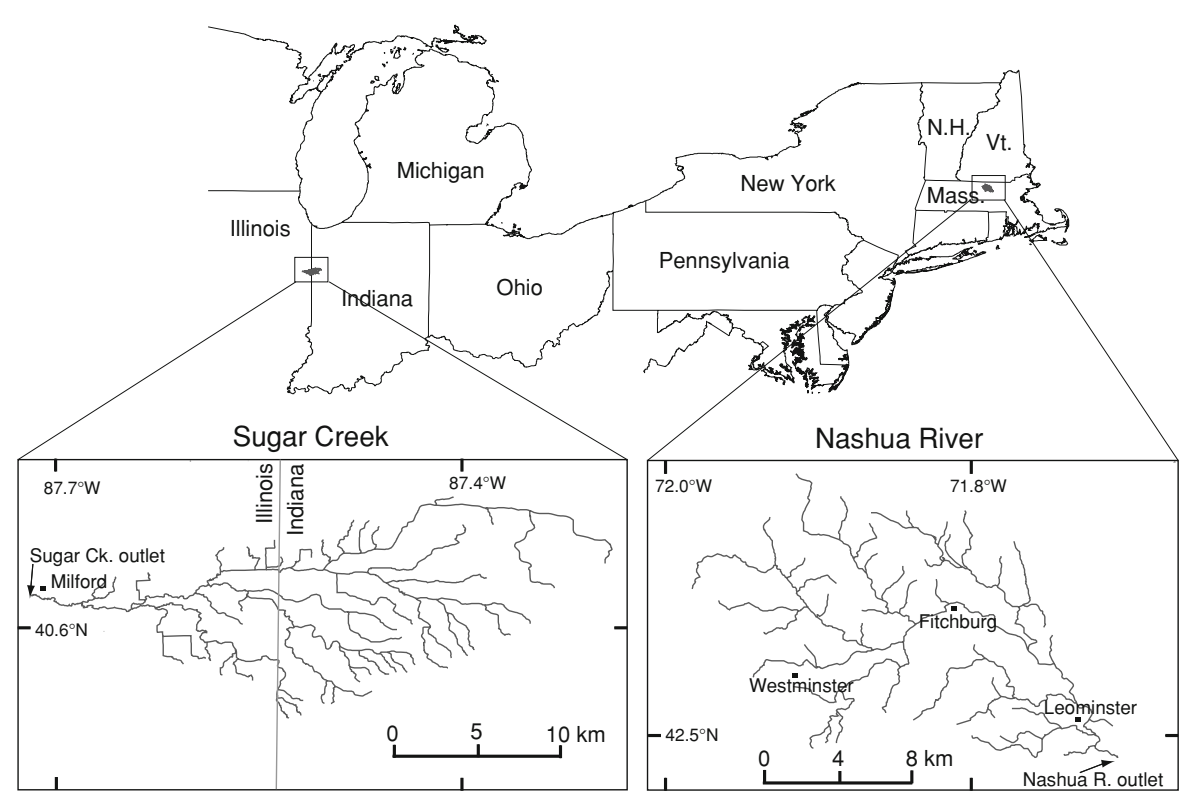

Field denitrification data and regression models

We selected three studies from the literature with sufficient data to develop regression-based estimates of the effects of denitrification on stream nitrate removal as a function of hydrological and biogeochemical rate-controlling properties. The regression equations are used to estimate the denitrification reaction rate constant $k$ in the transport simulation model (Eq. 1). Despite numerous studies of stream denitrification reported in the literature (e.g., see reviews by Pina-Ochoa and Alvarez-Cobelas 2006; Birgand et al. 2007), those selected for use in our modeling simulations are among the few studies that quantify denitrification effects on nitrogen removal at the reach scale, based on the use of ancillary chemical tracers and/or hydrological and chemical monitoring data (e.g., water time of travel, discharge). The selected studies also have a comprehensive set of field and laboratory measurements (Table 1), including areal denitrification and/or reaction rate constants, and measurements of discharge, water velocity, depth, and stream nitrate concentration (see Fig. 2). Other rate-controlling variables, such as organic matter and sediment grain size, were determined in these studies and were previously reported as partially explaining variability in the rates of nitrate removal (Royer et al. 2004; Smith et al. 2006; Opdyke et al. 2006; Opdyke and David 2007;
Mulholland et al. 2008, 2009); however, these properties were excluded from the analysis here because they are difficult to estimate for all streams in the river networks of the Sugar Creek and Nashua watersheds. Moreover, we are interested in evaluating the effects of stream properties that can be more readily generalized for watersheds and the NHD river network. The field measurements reflect withinchannel processes and do not include the effects of floodplains and backwater areas that can become important during high flows (e.g., Richardson et al. 2004).

The LINX (Lotic Intersite Nitrogen experiment; Mulholland et al. 2008) reach-scale measurements include in situ denitrification reaction rate constants (per unit time) derived from ${ }^{15} \mathrm{~N}$ isotopic tracer studies (Mulholland et al. 2008, 2009), based on spring or summer measurements from 49 streams within 8 biomes of the United States, sampled once during 2003-2006 $(n=49)$. Measurements of total nitrogen assimilation available from the LINX studies (Mulholland et al. 2009; Hall et al. 2009) are not evaluated in this analysis.

The US Geological Survey data (USGS) (Smith et al. 2006; Böhlke et al. 2008) include measurements of denitrification in sediment cores in stream reaches in the Iroquois River and Sugar Creek watersheds in Illinois and Indiana (1st through 4th order streams), based on repeated sampling over a range of discharge 
Table 1 Statistical summary of denitrification measurements from selected field datasets

\begin{tabular}{|c|c|c|c|c|c|c|c|}
\hline \multirow[t]{2}{*}{ Experimental field data and property ${ }^{\mathrm{a}}$} & \multicolumn{7}{|c|}{ Percentiles of the observations } \\
\hline & Minimum & 10 th & 25 th & Median & 75th & 90th & Maximum \\
\hline \multicolumn{8}{|c|}{ USGS ( $n=28$ cross-section; $n=170$ individual) } \\
\hline Discharge $\left(\mathrm{m}^{3} \mathrm{~s}^{-1}\right)$ & 0.029 & 0.043 & 0.121 & 0.564 & 1.25 & 13.23 & 19.51 \\
\hline Water depth (m) & 0.056 & 0.105 & 0.108 & 0.252 & 0.493 & 1.32 & 2.12 \\
\hline Nitrate concentration $\left(\mu \mathrm{mol} \mathrm{N} 1^{-1}\right)$ & 15 & 23 & 46 & 102 & 737 & 931 & 961 \\
\hline Reaction rate constant $\left(k ;\right.$ day $\left.^{-1}\right)$ & $<0.001$ & 0.009 & 0.044 & 0.160 & 0.580 & 1.11 & 4.04 \\
\hline Mass-transfer rate $\left(V_{f} ; \mathrm{m} \mathrm{day}^{-1}\right)$ & $<0.001$ & 0.008 & 0.019 & 0.044 & 0.085 & 0.143 & 0.673 \\
\hline Benthic areal rate $\left(U ; \mu\right.$ mol $\left.\mathrm{N} \mathrm{m}^{2} \mathrm{~h}^{-1}\right)$ & 4 & 55 & 102 & 231 & 544 & 1,125 & 4,371 \\
\hline \multicolumn{8}{|l|}{ LINX $(n=49)$} \\
\hline Discharge $\left(\mathrm{m}^{3} \mathrm{~s}^{-1}\right)$ & 0.001 & 0.003 & 0.005 & 0.013 & 0.049 & 0.112 & 0.189 \\
\hline Water depth (m) & 0.016 & 0.040 & 0.072 & 0.108 & 0.188 & 0.266 & 1.122 \\
\hline Nitrate concentration $\left(\mu \mathrm{mol} \mathrm{N} 1^{-1}\right)$ & $<1$ & 0.7 & 4 & 13 & 37 & 86 & 1,512 \\
\hline Reaction rate constant $\left(k ;\right.$ day $\left.^{-1}\right)$ & 0.034 & 0.106 & 0.178 & 0.533 & 1.54 & 3.71 & 117 \\
\hline Mass-transfer rate $\left(V_{f} ; \mathrm{m} \mathrm{day}^{-1}\right)$ & 0.002 & 0.012 & 0.026 & 0.068 & 0.166 & 0.372 & 12.74 \\
\hline Benthic areal rate $\left(U ; \mu \mathrm{mol} \mathrm{N} \mathrm{m}^{2} \mathrm{~h}^{-1}\right)$ & $<1$ & 4 & 13 & 42 & 135 & 239 & 655 \\
\hline \multicolumn{8}{|l|}{ ODR $(n=117)$} \\
\hline Discharge $\left(\mathrm{m}^{3} \mathrm{~s}^{-1}\right)$ & 0.005 & 0.025 & 0.066 & 0.214 & 0.668 & 1.04 & 1.70 \\
\hline Water depth (m) & 0.140 & 0.197 & 0.345 & 0.470 & 0.660 & 0.819 & 1.31 \\
\hline Nitrate concentration $\left(\mu \mathrm{mol} \mathrm{N} 1^{-1}\right)$ & 9 & 89 & 311 & 529 & 720 & 824 & 1,011 \\
\hline Reaction rate constant $\left(k ;\right.$ day $\left.^{-1}\right)$ & $<0.001$ & 0.001 & 0.005 & 0.034 & 0.087 & 0.300 & 8.39 \\
\hline Mass-transfer rate $\left(V_{f} ; \mathrm{m} \mathrm{day}^{-1}\right)$ & $<0.001$ & $<0.001$ & 0.002 & 0.016 & 0.044 & 0.113 & 1.51 \\
\hline Benthic areal rate $\left(U ; \mu \mathrm{mol} \mathrm{N} \mathrm{m}^{2} \mathrm{~h}^{-1}\right)$ & 2 & 9 & 32 & 228 & 857 & 1,660 & 5,108 \\
\hline
\end{tabular}

a The field datasets include USGS (Smith et al. 2006; Böhlke et al. 2008), LINX (Mulholland et al. 2008, 2009), ODR (Royer et al. 2004; Opdyke et al. 2006; Opdyke and David 2007). Definitions for the denitrification rate symbols are presented in Eq. 2

conditions during five sampling events from 1999 to 2001. The sampling includes 170 laboratory denitrification measurements of intact sediment cores (areal rate measures) with associated stream cross-section measurements of concentration and hydraulics, and 28 cross-sectional averaged measurements of reaction rate constants (units of time ${ }^{-1}$ ) based on the sediment core data; specific discharge (product of water velocity and depth) associated with individual sediment cores is used to compute weighted cross-section averages.

The ODR (Opdyke-David-Royer) denitrification measurements (Royer et al. 2004; Opdyke et al. 2006; Opdyke and David 2007) are from four headwater and second-order agricultural streams in Illinois. Denitrification measurements $(n=117)$ are from the application of acetylene inhibition techniques to laboratory sub-samples of benthic sediment core composites extracted from the streams seasonally from 2001 to 2005 and incubated at stream temperatures in the laboratory. The laboratory data are associated with reach-scale measurements of discharge, water depth and velocity, and nitrate concentration. Stream water temperatures ranged from average lows in February of $2.8^{\circ} \mathrm{C}$ to average summer highs of $19.3^{\circ} \mathrm{C}$., with average spring and fall temperatures of $10.9^{\circ} \mathrm{C}$.

Using these literature data, we estimated a total of five regression models that describe the denitrification rates as a function of water discharge or depth, stream nitrate concentration, and temperature-related seasonality. The models include three regression equations for the reaction rate constant $k$ (one from each field study; LINX, USGS and ODR based on Eq. 3), and two regression equations for the benthic areal rate $U$ (USGS and ODR studies only based on Eq. 4) as determined from laboratory measurements of sediment cores. Regressions were estimated for both $k$ and $U$ to allow comparisons of the results from the transport model simulations that are specific to 
Fig. 2 Observed measures of the reaction rate constant $k$ for the separate field data sets, plotted as a function of a nitrate concentration, $\mathbf{b}$ discharge, and $\mathbf{c}$ water depth. The field datasets include USGS (Smith et al. 2006; Böhlke et al. 2008), LINX (Mulholland et al. 2008, 2009), ODR (Royer et al. 2004; Opdyke et al. 2006; Opdyke and David 2007). The slope of the line in (c) is expected for a

constant mass-transfer rate, $V_{f}$ (a) Nitrate concentration

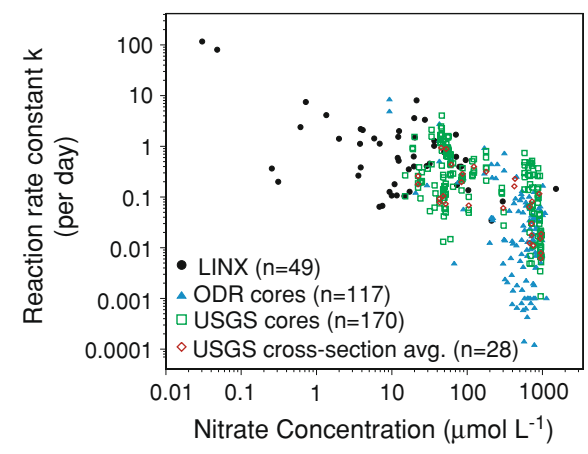

(c) Water depth

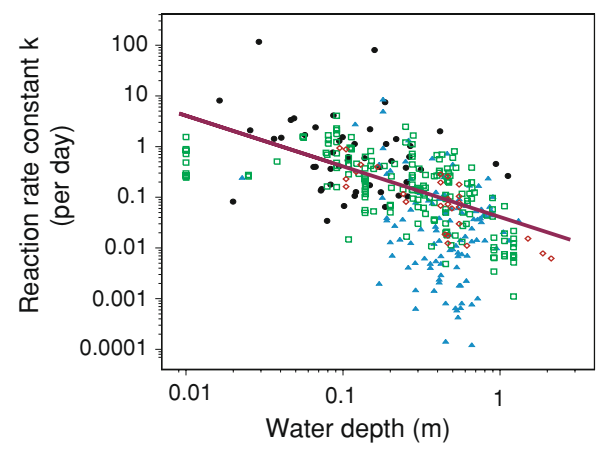

Water depth $(\mathrm{m})$ (b) Streamflow

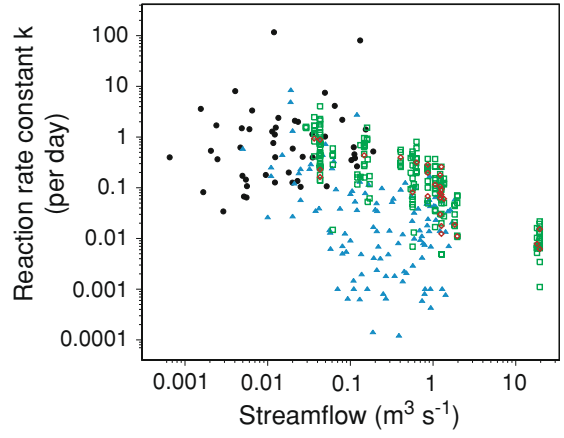

the denitrification rates that were most directly measured in the field studies. For the ODR data set, a continuous seasonal variable is included to describe temperature-related effects on denitrification that were previously reported (Opdyke and David 2007); these effects have not been reported in the other studies, where measurements are typically restricted to the warmer periods of the year.

The most fully specified form of the reaction rate constant regressions (applied to the LINX, USGS and ODR data) estimates $k_{m}$ for the $m$ th field observation as a function of the water-column nitrate concentration, $C_{m}$, the hydrological condition, $H_{m}$ [characterized by either the mean discharge $\left(Q_{m}\right)$ or mean water depth $\left(d_{m}\right)$ ], and seasonal temperaturerelated variability (ODR model only) as described by trigonometric functions of decimal time $(T)$, such that

$k_{m}=b_{0} C_{m}^{b 1} H_{m}^{b 2}\left[\sin \left(2 \pi T_{m}\right)\right]^{b 3}\left[\cos \left(2 \pi T_{m}\right)\right]^{b 4} \varepsilon_{m}$

where $b_{1, \ldots, b_{4}}$ are estimated dimensionless coefficients, $b_{O}$ is an estimated model intercept with units of the reaction rate constant, and $\varepsilon_{m}$ is the model error. The trigonometric functions provide an indirect measure of the water temperature-related effects for the ODR field data.

The most fully specified form of the benthic areal denitrification rate regressions (applied to the USGS and ODR data only) is described according to

$U_{m}=b_{0}^{\prime} C_{m}^{b_{1}^{\prime}} H_{m}^{b_{2}^{\prime}}\left[\sin \left(2 \pi T_{m}\right)\right]^{b_{3}^{\prime}}\left[\cos \left(2 \pi T_{m}\right)\right]^{b_{4}^{\prime}} \varepsilon_{m}^{\prime}$

where $b_{1, \ldots}^{\prime}, b_{4}^{\prime}$ are estimated dimensionless coefficients for the areal rate model, $b_{O}^{\prime}$ is an estimated model intercept with units of the benthic areal denitrification rate, and $\varepsilon_{m}^{\prime}$ is the error of the areal rate model. We calculate the corresponding reaction rate constant from the benthic areal rate in Eq. 4 according to

$k_{m}=\frac{U_{m}}{C_{m} d_{m}}$.

The model coefficients in Eqs. $(3,4)$ are estimated by log-linear regression, based on natural log transformations of the response and explanatory variables. The model errors are assumed to be independently and identically distributed as a normal random variable with mean zero and standard deviation $\sigma$; we evaluated the residuals for adherence to these 
assumptions. Predictions of the mean reaction rate constant or benthic areal rate, based on values of the explanatory variables in the model application to the river networks of the two watersheds (Appendix "Predicting reaction rate constants for Sugar Creek and Nashua streams"), are re-transformed via exponentiation to original units and corrected for log retransformation bias using Ferguson or Smearing type (Cohn et al. 1992) correction factors [Eqs. A1-A3]. This correction adjusts for the intrinsic negative bias in re-transformed predictions from log-linear functions (Cohn et al. 1992) - i.e., uncorrected predictions reflect the median rather than the mean response conditioned on the values of the explanatory factors. Correction for re-transformation bias in the experimental models evaluated here shifts the uncorrected predicted values of the reaction rate constant upward by a factor of 1.14-3.0. The size of the correction factor is generally dependent upon the magnitude of the variance in regression model.

Application of the nitrate transport model to the river networks

The stream nitrate transport model is applied to the two watersheds using hydrological and chemical data for each stream reach by sequentially executing Eq. 1 in hydrological downstream order, beginning with the smallest first-order streams and proceeding to the largest fourth-order streams. The simulations include separate model executions for each of the three field data sets (LINX, USGS and ODR) using parameters from the three reaction rate constant regression equations (in "Predicting reaction rate constants for Sugar Creek and Nashua streams" of the Appendix). We also ran model simulations and evaluated the results using parameters from the two benthic areal rate regression equations (USGS and ODR studies only), which were converted to reaction rate constants (Eq. A3) for use in the transport model. The model simulation results using the benthic areal rate equations are generally similar to those based on the reaction rate constant equations. Thus, to simplify the presentation, we only report the final results for the model predictions of reach-level nitrate removal based on parameters from the reaction rate constant regressions (Eq. A1). The simulations were executed for 20 years of estimated monthly data for the Sugar Creek watershed, consisting of 240 monthly values of lateral nitrate loadings and hydraulic properties, and for 7 years for the Nashua watershed, consisting of 84 monthly values (see "Stream hydrological estimates" and "Lateral loadings of nitrate to streams" in the Appendix for further details).

We report monthly reach-level predictions of nitrate removal by denitrification from the transport model, expressed as the fraction (\%) of in-stream nitrate flux removed per length (kilometer) of stream channel (Eq. A9; see "Stream nitrate removal metrics" of the Appendix). This calculation is based on predictions of in-stream nitrate flux and nitrate removal during transit through fixed reaches as defined by the NHD river network. We also report the monthly mass of the in-stream nitrate flux removed per length (meter) of stream channel (Eq. A10). The simulations are also executed for annual hydrological and biogeochemical conditions (e.g., mean annual discharge, velocity, depth and nitrate lateral loadings) to provide parallel predictions of the mean annual nitrate removal in streams for comparison with the monthly predictions of nitrate removal. Model predictions of the annual in-stream nitrate removal based on annual data are generally similar to those based on aggregated monthly predictions.

We evaluate the separate hydrological and biogeochemical effects on denitrification and nitrate removal in streams through sensitivity evaluations of the modeled response of the fraction of in-stream nitrate flux removed per kilometer of channel to changes in these factors (Table 2). We evaluate the response of the monthly nitrate removal fraction to $0.1,0.5,2$ and 10-fold changes in streamflow and nitrate lateral loading (Table 2). Our assessment of the biogeochemical factors examines the response of the nitrate removal fraction to changes in the nitrate lateral loadings to streams while holding discharge and related properties (water depth, velocity) constant. This simulates changes in nitrate loadings and in-stream concentrations in response to changes in the supply of nitrate to watersheds. For each monthly realization, we assume a constant nitrate concentration in the lateral loadings (runoff and ground-water discharge) to the reaches throughout a given watershed. Our assessment of the hydrological factors evaluates the effect of changes in discharge and associated hydraulic properties (velocity, depth) while holding the nitrate concentration of the lateral 


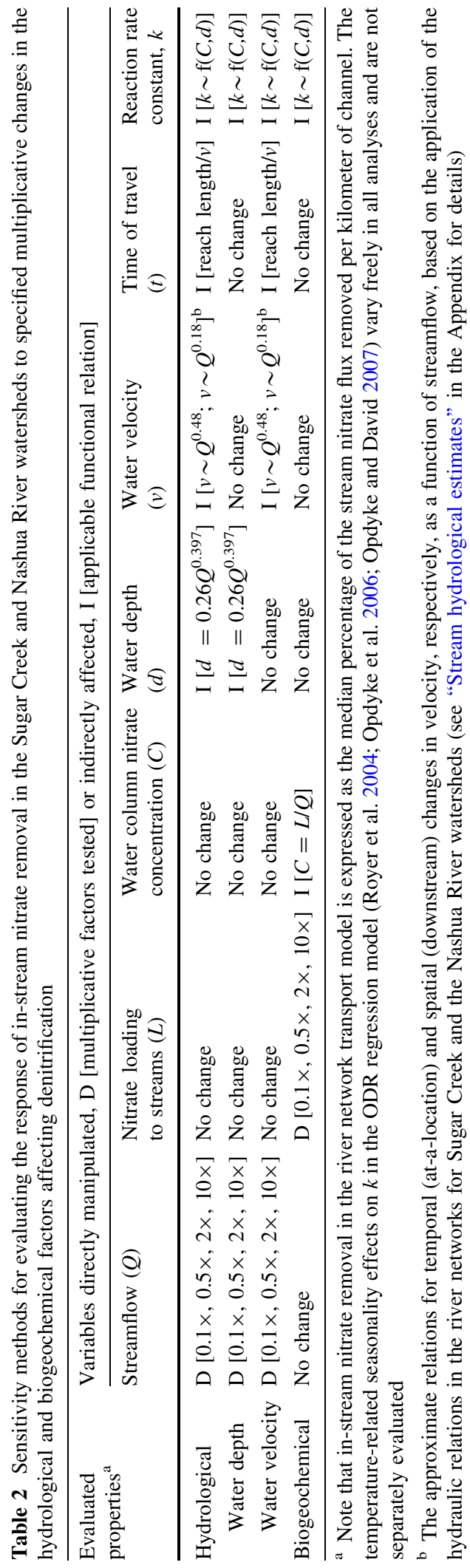

loadings constant for all realizations. We also simulate the separate effects of water velocity and water depth on nitrate removal. Our evaluation of the response of the nitrate removal fraction over an order-of-magnitude change in nitrate loadings and discharge generally covers the range of seasonal and spatial variability in these properties in the river networks of the case study watersheds.

\section{Results and discussion}

Field denitrification data and regression models

The estimates of nitrate removal by denitrification from the three field studies (Table 1) are given as reaction rate constants $(k)$, benthic areal rates $(U)$, and mass-transfer rates $\left(V_{f}\right)$. Each of the rates ranges over at least three orders of magnitude, although most observations (10th-90th percentiles) span about two orders of magnitude. The rate constants $(k)$ are generally highest for the LINX data, which are mostly from streams with relatively low nitrate concentration. Despite general similarities in the range of the USGS and ODR $U$ values and nitrate concentrations, USGS values of $k$ and $V_{f}$ are higher than those for the ODR data by more than a factor of two, owing to the more frequently sampled higher nitrate concentrations at the ODR stream sites (Table 1; Eq. 2). The USGS data have the broadest coverage of discharge regimes; the interquartile range extends from 0.12 to $1.25 \mathrm{~m}^{3} \mathrm{~s}^{-1}$, which is twice as large as that for the ODR values and more than a factor of 25 higher than that for the LINX observations.

Measures of the regression model fit and statistical significance of the regression parameters (Table 3) indicate that the benthic areal rates and the reaction rate constants are correlated (Fig. 2) with nitrate concentration, measures of hydrology (discharge, water depth), and temperature-related seasonality (ODR model only). The estimated regression parameters (Table 3) have similar features to those previously reported (Smith et al. 2006; Opdyke and David 2007; Mulholland et al. 2008, 2009; Böhlke et al. 2008). Note that the reaction rate constants of the regressions are correlated with nitrate concentration and water depth, based on their calculation (Eq. 2) from benthic areal rates (USGS, ODR) or 
Table 3 Results of the regressions of denitrification rates as a function of stream nitrate concentration, hydrological condition, and temperature-related seasonality for the field datasets

\begin{tabular}{|c|c|c|c|c|c|}
\hline \multirow{3}{*}{$\begin{array}{l}\text { Model terms and coefficients } \\
\mathrm{a}^{\mathrm{a}} \\
\text { Denitrification rate; model } \\
\text { response variable } \text { (units) }^{\mathrm{b}}\end{array}$} & \multicolumn{2}{|l|}{ USGS } & \multirow{3}{*}{$\begin{array}{l}\text { LINX } \\
\text { Reach } \\
\text { measurements } \\
\text { Rate constant } \\
k\left(\text { day }^{-1}\right)\end{array}$} & \multirow{2}{*}{\multicolumn{2}{|c|}{$\begin{array}{l}\text { ODR } \\
\text { Sub-samples of cross-section } \\
\text { composites of cores }\end{array}$}} \\
\hline & \multirow{2}{*}{$\begin{array}{l}\text { Core samples } \\
\text { Benthic areal } U \\
\left(\mu \mathrm{mol} \mathrm{N} \mathrm{m}^{2} \mathrm{~h}^{-1}\right)\end{array}$} & \multirow{2}{*}{$\begin{array}{l}\text { Cross-section } \\
\text { average } \\
\text { Rate constant } \\
k\left(\text { day }^{-1}\right)\end{array}$} & & & \\
\hline & & & & $\begin{array}{l}\text { Benthic areal } \\
U\left(\mu \mathrm{mol} \mathrm{N} \mathrm{m}^{2} \mathrm{~h}^{-1}\right)\end{array}$ & $\begin{array}{l}\text { Rate constant } \\
k\left(\text { day }^{-1}\right)\end{array}$ \\
\hline \multicolumn{6}{|l|}{ Model explanatory variables: } \\
\hline \multicolumn{6}{|l|}{ Nitrate concentration $\left(\mu \mathrm{mol} 1^{-1}\right)\left[b_{1}\right]$} \\
\hline Mean & 0.645 & -0.524 & -0.478 & 0.340 & -0.786 \\
\hline Standard error & 0.054 & 0.076 & 0.092 & 0.249 & 0.226 \\
\hline$P$ value & $<0.001$ & $<0.001$ & $<0.001$ & 0.174 & 0.001 \\
\hline Hydrology (discharge or depth) $\left[b_{2}\right]$ & Discharge $\left(\mathrm{m}^{3} \mathrm{~s}^{-1}\right)$ & Depth (m) & Depth (m) & Discharge $\left(\mathrm{m}^{3} \mathrm{~s}^{-1}\right)$ & Depth (m) \\
\hline Mean & -0.095 & -1.097 & -0.612 & 0.038 & -0.309 \\
\hline Standard error & 0.041 & 0.122 & 0.221 & 0.166 & 0.325 \\
\hline$P$ value & 0.022 & $<0.001$ & 0.008 & 0.819 & 0.343 \\
\hline \multicolumn{6}{|l|}{ Season, sine of decimal time $\left[b_{3}\right]$} \\
\hline Mean & N.A. & N.A. & N.A. & -0.885 & -0.883 \\
\hline Standard error & N.A. & N.A. & N.A. & 0.330 & 0.300 \\
\hline$P$ value & N.A. & N.A. & N.A. & 0.008 & 0.004 \\
\hline \multicolumn{6}{|l|}{ Season, cosine of decimal time $\left[b_{4}\right]$} \\
\hline Mean & N.A. & N.A. & N.A. & -0.732 & -0.691 \\
\hline Standard error & N.A. & N.A. & N.A. & 0.242 & 0.229 \\
\hline$P$ value & N.A. & N.A. & N.A. & 0.003 & 0.003 \\
\hline \multicolumn{6}{|l|}{ Intercept $\left[b_{0}\right]$} \\
\hline $\begin{array}{l}\text { Mean (natural } \log \text { of the } \\
\text { denitrification rate units) }\end{array}$ & 2.211 & -0.785 & -0.582 & 2.757 & 0.336 \\
\hline Standard error & 0.301 & 0.464 & 0.540 & 1.668 & 1.516 \\
\hline$P$ value & $<0.001$ & 0.103 & 0.286 & 0.101 & 0.825 \\
\hline \multicolumn{6}{|l|}{ Model statistics: } \\
\hline Number of observations & 170 & 28 & 49 & 117 & 117 \\
\hline RMSE (root mean square error) & 0.836 & 0.508 & 1.308 & 1.825 & 1.741 \\
\hline$R^{2}$ & 0.495 & 0.878 & 0.409 & 0.122 & 0.394 \\
\hline Log re-transform bias correction factor & 1.32 & 1.14 & 1.90 & 3.28 & 2.99 \\
\hline
\end{tabular}

a The field datasets include USGS (Smith et al. 2006; Böhlke et al. 2008), LINX (Mulholland et al. 2008, 2009), ODR (Royer et al. 2004; Opdyke et al. 2006; Opdyke and David 2007); N.A. = not applicable

b The regression for response variable $k$ is based on Eq. 3; the regression for response variable $U$ is based on Eq. 4

mass-transfer rates (LINX); however, the regressions have utility for quantifying the functional dependence of $k$ on these rate-controlling variables in the river network model simulations (also, as noted in the methods section, the different denitrification rate expressions of $k$ and $U$ gave generally similar predictions of the nitrate removal fractions in the transport model simulations).
The reported measures of regression model accuracy include $R^{2}$ and RMSE (Root Mean Square Error; Table 3), and the relative accuracy of the predictions of $k$ (or $U$ ) expressed by $95 \%$ prediction intervals (Table 4); note that these metrics can be compared only among models with the same response variable. The $95 \%$ prediction intervals include uncertainties in the regression coefficients and the residual variance 
Table 4 Statistical measures of the relative accuracy of the predictions of the reaction rate constant $k$ and benthic areal rate $U$, based on regression models for the field datasets

\begin{tabular}{|c|c|c|c|c|c|c|c|}
\hline \multirow[t]{2}{*}{ Field denitrification regression model ${ }^{\mathrm{a}}$} & \multicolumn{7}{|c|}{$\begin{array}{l}\text { Percentiles of the } 95 \% \text { prediction interval values }{ }^{\mathrm{b}} \text { ( } 95 \% \text { prediction intervals expressed as } \\
\text { a percentage of the predicted mean rate corresponding to the interval) }\end{array}$} \\
\hline & Minimum & 10th & 25 th & Median & 75 th & 90th & Maximum \\
\hline \multicolumn{8}{|l|}{ USGS } \\
\hline Benthic areal rate $(U ; n=170)$ & 26 & 30 & 37 & 41 & 47 & 58 & 67 \\
\hline Reaction rate constant $(k ; n=28)$ & 43 & 49 & 56 & 68 & 84 & 87 & 99 \\
\hline LINX reaction rate constant $(k ; n=49)$ & 77 & 80 & 91 & 117 & 144 & 231 & 364 \\
\hline \multicolumn{8}{|l|}{ ODR $(n=117)$} \\
\hline Benthic areal rate $(U)$ & 112 & 122 & 134 & 150 & 171 & 209 & 416 \\
\hline Reaction rate constant $(k)$ & 100 & 112 & 127 & 141 & 157 & 179 & 603 \\
\hline
\end{tabular}

of the model, and would be expected to contain $95 \%$ of the observed data if the model assumptions are valid (all of the models generally satisfied the assumptions of normality and constant variance). The percentiles of the $95 \%$ prediction interval values (Table 4) indicate the relative accuracy of the predictions of $k$ (or $U$ ) over their range along the regression line; low $95 \%$ prediction interval values (e.g., minimum, 10th percentile) generally describe errors in predictions of $k$ (or $U$ ) in the vicinity of the mean, whereas high $95 \%$ prediction interval values (90th percentile, maximum) generally describe errors in predictions of $k$ (or $U$ ) closer to the tails of the regression line. The prediction accuracies in the vicinity of the mean predictions of $k$, based on the minimum of the distributions (Table 4), indicate that the errors range from a low of $43 \%$ for the USGS model to a high of $100 \%$ for the ODR model. The relative errors of the LINX model predictions are about $60-80 \%$ higher than those of the USGS model, whereas those of the ODR model are about 100$130 \%$ higher than those of the USGS model.

All of the regression models are consistent in indicating that the benthic areal rates and reaction rate constants vary nonlinearly with nitrate concentration, although the magnitude and statistical significance of the concentration-related response differs somewhat among the models (Table 3). Concentration is only significant in the ODR regression models if the temperature-related seasonal terms are included.
Concentration coefficients in the benthic areal rate regression models are less than 1 (and less than 0 in the reaction rate models), the expected values according to first-order kinetics. This indicates that nitrate removal from the water column by denitrification becomes less efficient with increases in concentration, a pattern that is suggestive of the effects of concentration saturation kinetics. Both areal rate regression models (USGS, ODR) indicate a less than proportional increase in the absolute quantities of nitrate mass removal with increasing concentration, which is consistent with a decrease in the reaction rate constant and masstransfer rate (Eq. 2) with increasing concentration (Table 3; Fig. 2a). Prior evaluations of the experimental data (Mulholland et al. 2009; Böhlke et al. 2008) do not provide conclusive evidence about whether the denitrification response to concentration is similar in form to Michaelis-Menten saturation kinetics. The Michaelis-Menten function provides a somewhat poorer statistical description of the spatial variability in the LINX denitrification and concentration measurements in comparison to that for a loglinear power function (Mulholland et al. 2009) as used in our study, whereas these two functional relations provide a generally similar statistical fit to the seasonal and discharge-related variation in USGS measurements (Böhlke et al. 2008).

The magnitude of the decline in the reaction rate constants with increasing nitrate concentrations (Fig. 2a) is generally consistent among the different 
Table 5 Sensitivity of the model predictions of the reaction rate constant $k$ to changes in the explanatory variables of the regression models for the field datasets

\begin{tabular}{|c|c|c|c|c|c|c|c|c|c|}
\hline \multirow{3}{*}{$\begin{array}{l}\text { Field reaction rate constant }(k) \text { regression } \\
\text { model }^{\mathrm{a}}\end{array}$} & \multicolumn{9}{|c|}{ Reaction rate constant ratio ${ }^{\mathrm{b}}$ (predicted $k$ for changed variable/predicted $k$ for baseline) } \\
\hline & \multicolumn{4}{|c|}{ Nitrate Concentration } & \multicolumn{4}{|c|}{ Water Depth } & \multirow{2}{*}{$\begin{array}{l}\text { Temperature-related seasonality. } \\
\text { Maximum } \\
\text { annual change (Feb. to July) }\end{array}$} \\
\hline & $0.1 \mathrm{x}$ & $0.5 \mathrm{x}$ & $2 \mathrm{x}$ & $10 \mathrm{x}$ & $0.1 \mathrm{x}$ & $0.5 \mathrm{x}$ & $2 \mathrm{x}$ & $10 \mathrm{x}$ & \\
\hline USGS & 3.8 & 1.5 & 0.67 & 0.26 & 12.0 & 2.1 & 0.47 & 0.08 & - \\
\hline LINX & 3.0 & 1.4 & 0.72 & 0.33 & 4.1 & 1.5 & 0.65 & 0.24 & - \\
\hline ODR & 6.1 & 1.7 & 0.58 & 0.16 & 2.0 & 1.2 & 0.81 & 0.49 & 9.4 \\
\hline
\end{tabular}

${ }^{a}$ The field datasets include USGS (Smith et al. 2006; Böhlke et al. 2008), LINX (Mulholland et al. 2008, 2009), ODR (Royer et al. 2004; Opdyke et al. 2006; Opdyke and David 2007)

b The predicted response of the reaction rate constant is for a halving/doubling and an order-of-magnitude decrease/increase in the nitrate concentration and water depth variables, holding the other variables constant. The ODR model also includes an assessment of the reaction rate constant response to the maximum annual change caused by temperature-related seasonal variability. The baseline

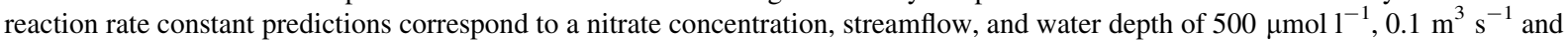
$0.105 \mathrm{~m}$, respectively; note that the ratio values are insensitive to the choice of the baseline conditions

field data sets over several orders of magnitude in concentration, from the less nitrate-enriched streams measured at many LINX sites to the highly nitrateenriched agricultural streams measured at the USGS and ODR sites (Table 3). Sensitivity analyses (Table 5) further indicate that the response of $k$ to order-of-magnitude changes in concentration, holding the other variables constant, is most similar for the USGS and LINX data (e.g., factor of 3- to 4-fold increase in $k$ for a 10-fold decrease in concentration), whereas the ODR response is much larger (e.g., 6fold increase in $k$ ). The ODR model also displays a large seasonal temperature-related response corresponding to a 9-fold change in $k$ during the year. The order-of-magnitude changes in nitrate concentration in the sensitivity analyses correspond approximately to the magnitude of the predicted changes in concentration in the case study streams evaluated in the model simulations.

The regression models (Table 3 ) indicate an inverse response of the reaction rate constant (and benthic areal rate) to stream discharge and water depth, independent of nitrate concentration, although the level of statistical significance varies among the models. The hydrological variables are generally more weakly correlated with the reaction rate constant than is nitrate concentration in all of the models. The use of stream discharge or water depth as an explanatory variable reflects coefficient significance and a desire for consistency among models with similar response variables. The sensitivity results (Table 5) indicate that the USGS predictions of $k$ are the most sensitive (i.e., 12-fold change) to 10-fold changes in water depth, whereas ODR predictions of $k$ are the least sensitive (i.e., 2-fold change). The influence of water depth in the models of $k$ is related in part to its depthdependent calculation, whereas the areal denitrification rate models (USGS, ODR; Table 3) may generally provide a more independent evaluation of biogeochemical effects on denitrification (see Böhlke et al. 2008). The predicted response of the benthic areal rates is generally consistent with the effects of discharge on denitrification, related to water and nitrate contact with benthic sediments in hyporheic zones (Peterson et al. 2001; Boyer et al. 2006; Mulholland et al. 2009).

Finally, it is important to recognize that spatial and temporal differences in the stream sampling characteristics and measurements of the separate field studies may impose some limits on our ability to fully explain differences in the nitrate concentration and water depth coefficients among the various regression models (Table 3). Ambiguities may arise from site-specific differences in the effects of the underlying nitrate concentration and discharge relations on denitrification, effects that may vary between sampling sites and between the different field data sets. For example, changes in denitrification and concentration with discharge in the USGS data primarily reflect temporal differences at relatively few sites with relatively uniform land use, whereas the LINX data reflect site-to-site differences across 
varied land uses that could be associated with other properties that control the rates of denitrification.

Application of the nitrate-transport model to Sugar Creek and Nashua watersheds

We present the simulation results from the nitrate transport model (Eq. 1) in four sections. The first section describes the discharge values and nitrate loadings used as inputs to the model; we also present the model predictions of water-column nitrate concentrations for the river networks. The second section presents model predictions of the relative stream nitrate removal per unit channel length (Eq. A9) and the analyses of the sensitivity of the model predictions of nitrate removal to changes in hydrological and biogeochemical factors. The third section presents model predictions of the mass nitrate removal per unit channel length (Eq. A10). A final section discusses the implications of the predictions of stream nitrate removal for the downstream fate of nitrate in river networks.
Nitrate loading to streams, discharge and predicted nitrate concentration

Monthly variations in nitrate concentrations and yield show seasonal patterns that are strongly related to intra-annual variability in discharge (Fig. 3). The monthly values of nitrate yield $\left(\mathrm{kg} \mathrm{km}^{-2}\right.$ year $\left.^{-1}\right)$ are used as lateral loadings in the model simulations for each of the reaches in the case study river networks and are based on monitoring records at a nearby site on Sugar Creek (downstream gage) and the Stillwater River (adjacent to the Nashua watershed; see "Lateral loadings of nitrate to streams" of the Appendix). The highest yields generally occur during the high-discharge periods of the year, extending from February to June, whereas the lowest yields occur from July to October. The 10th and 90th percentiles reveal considerable variation over the periods of 1982-2001 (Sugar Creek) and 1995-2001 (Stillwater River), which are reflected in the lateral nitrate loadings used in the river network simulations. The monitoring data for Sugar Creek display a

(a) Sugar Creek at Milford, Illinois
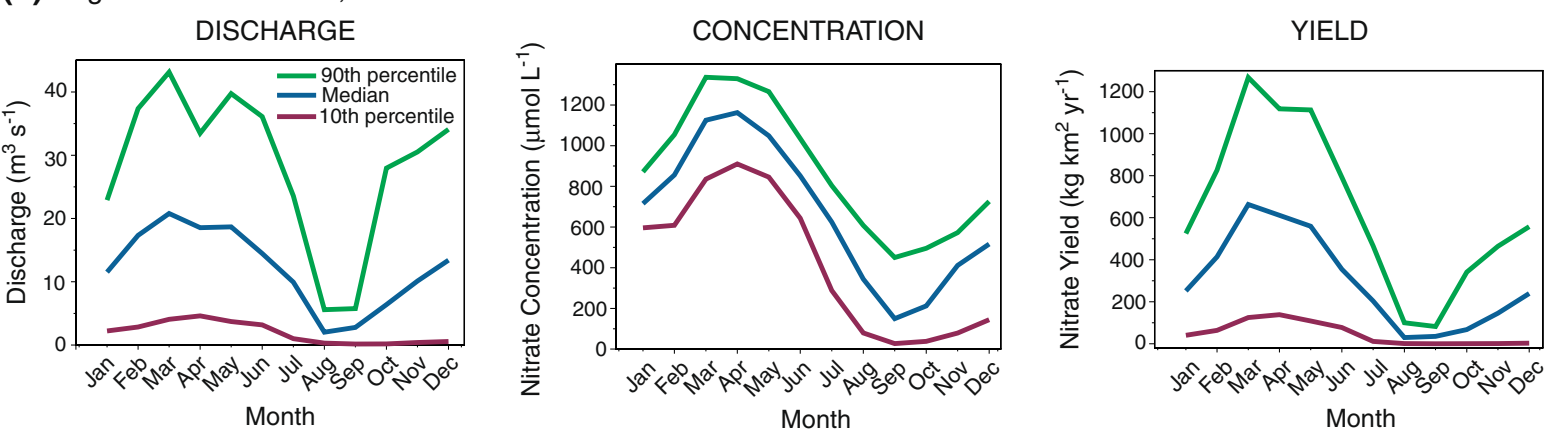

(b) Stillwater River near Sterling, Massachusetts
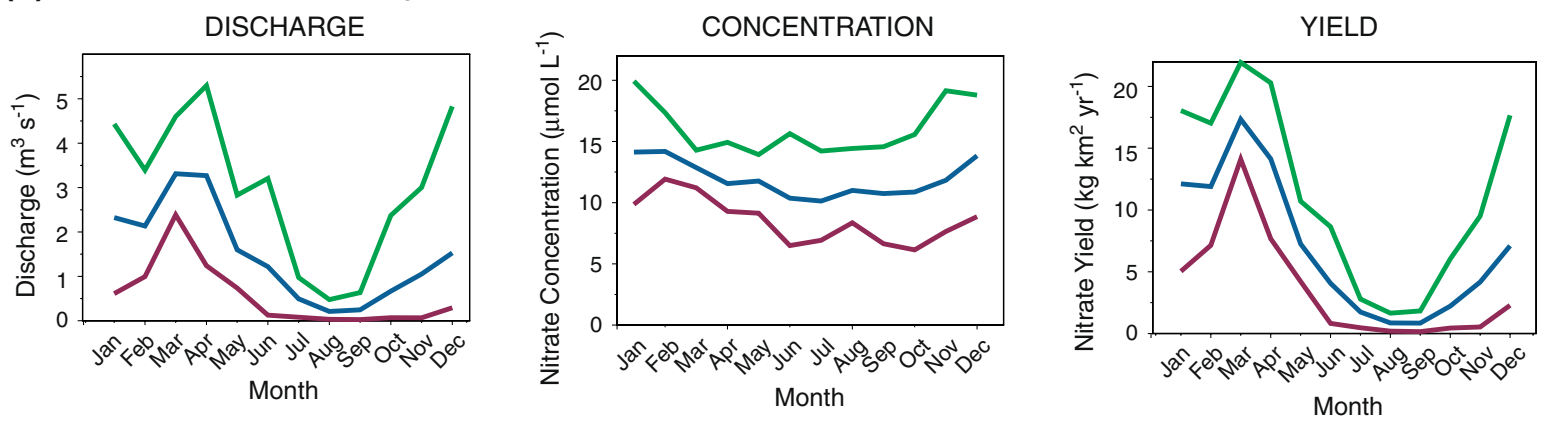

Fig. 3 Monthly discharge, nitrate concentration, and nitrate yield for monitoring stations used to derive the lateral nitrate loadings to streams for Sugar Creek at Milford, Illinois and Stillwater River near Sterling, MA. Intervals on the graphs display the median and the 10th and 90th percentiles for monthly values during the period 1982-2001 at Sugar Creek and 1995-2001 for Stillwater River 
concentration-discharge relation with a large discharge exponent that reflects the underlying importance of diffuse agricultural sources of nitrate and the effects of artificial subsurface drainage in the catchment. The nitrate concentrations in the Stillwater River are less strongly correlated with discharge, reflecting the combined contributions of diffuse and municipal wastewater sources in the basin. Nitrate concentrations are also substantially lower in the Stillwater River than in Sugar Creek.

The discharge values and predicted nitrate concentrations in the river network simulations show similar seasonal and spatial patterns over the range of stream sizes in the Sugar Creek and Nashua watersheds (Fig. 4). The discharge values for the two watersheds also span a similar range across the different stream sizes (note that total runoff in the Sugar Creek modeled watershed is about $60 \%$ of that in the Nashua watershed related to Sugar Creek's larger drainage area). By contrast, the stream nitrate concentrations (based on predictions from the LINX regression parameters; Fig. 4) differ by one to more than two orders of magnitude between the two watersheds. The nitrate concentrations in each of the watersheds display appreciable seasonal variation, from a factor of four to more than an order of magnitude. The relative seasonal variations in predicted nitrate concentrations from simulations based on USGS and ODR regression parameters are generally larger than those shown in Fig. 4 based on the LINX regression parameters. Predicted nitrate concentrations also show stream-size related differences that vary by season (Fig. 4). The stream-size related differences in concentrations reflect seasonal differences in the rates of nitrate removal in headwater and other low-order streams that govern the nitrate mass delivery to downstream higher order streams (see following sections).

\section{Relative nitrate removal by denitrification in streams}

We describe both temporal (seasonal) and spatial (stream-size related) patterns in simulated stream nitrate removal by denitrification in the river networks (Fig. 5). As shown in Fig. 5, we express nitrate removal by denitrification according to monthly and annual median values of the fraction $(\%)$ of the instream nitrate flux removed per kilometer of stream channel in each of four stream orders. The nitrate removal fraction shows many similarities in both
Fig. 4 Median discharge and nitrate concentration in streams of the Sugar Creek and Nashua River networks. Nitrate concentrations are predicted based on the application of the LINX field data (Mulholland et al. 2008,2009 ) in the river network simulation model (a) Discharge
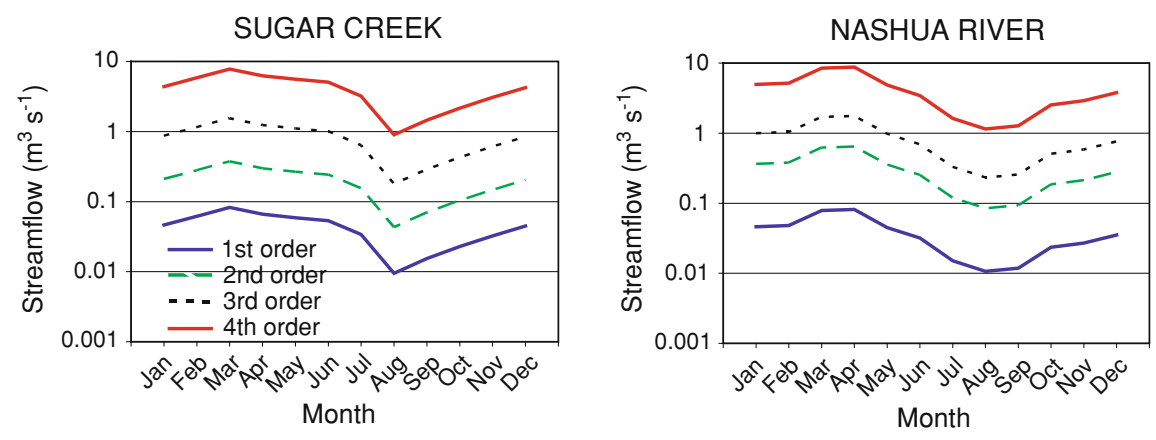

(b) Concentration

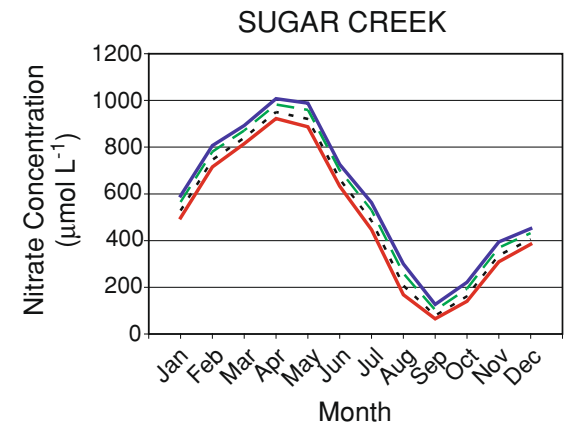


Fig. 5 Median percentage of the in-stream nitrate flux removed per kilometer of channel in streams of the Sugar Creek and Nashua River watersheds by strahler stream order, reported for the reaction rate constant regressions for the field datasets: a LINX, b USGS, and c ODR. The field datasets include USGS (Smith et al. 2006; Böhlke et al. 2008), LINX

(Mulholland et al. 2008, 2009), ODR (Royer et al. 2004; Opdyke et al. 2006; Opdyke and David 2007). The "annual" median percentages removed are based on model simulations executed for annual hydrological and waterquality measures (e.g., mean annual discharge, velocity, depth, and nitrate lateral loadings to streams)

\section{(a) LINX}
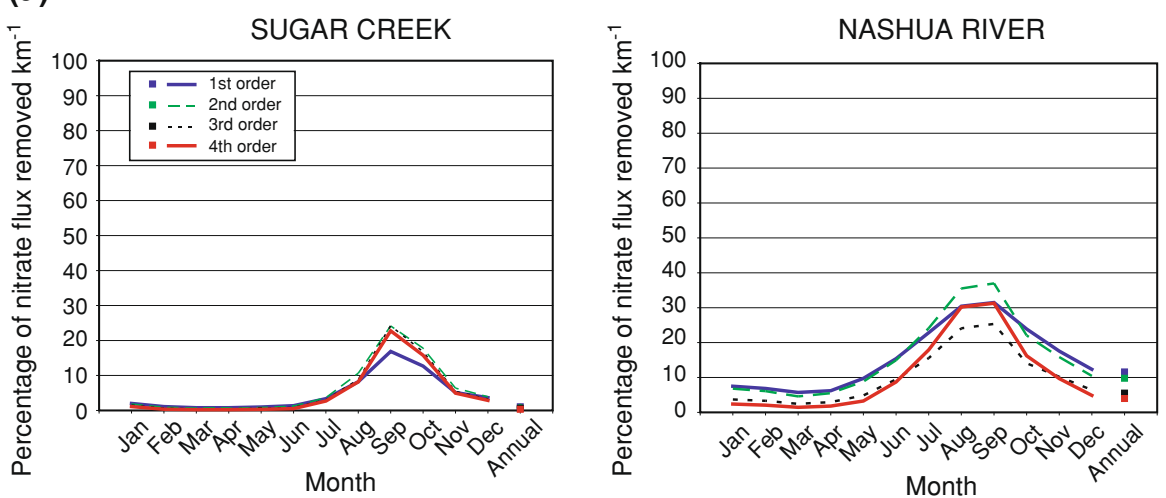

(b) USGS
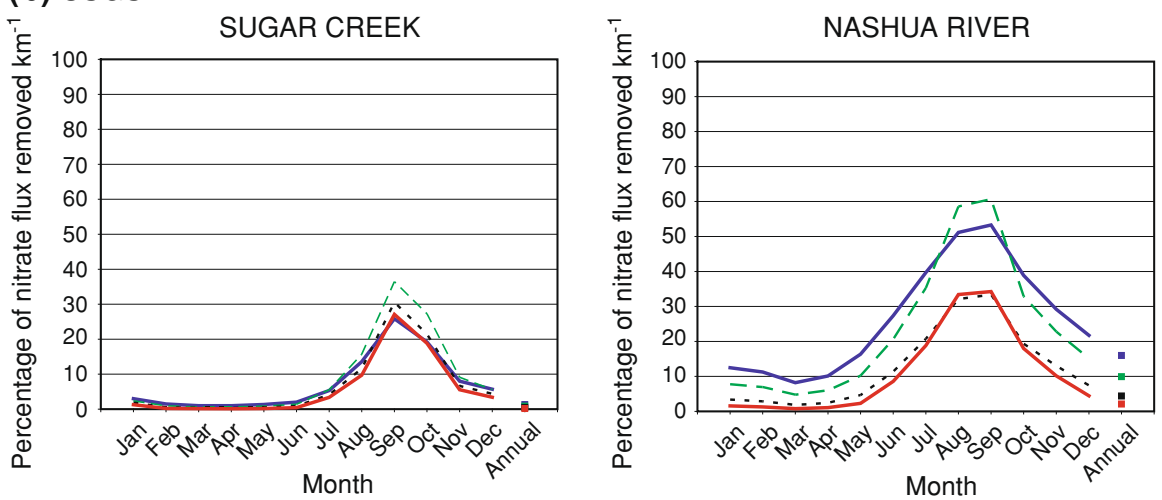

\section{(c) ODR}

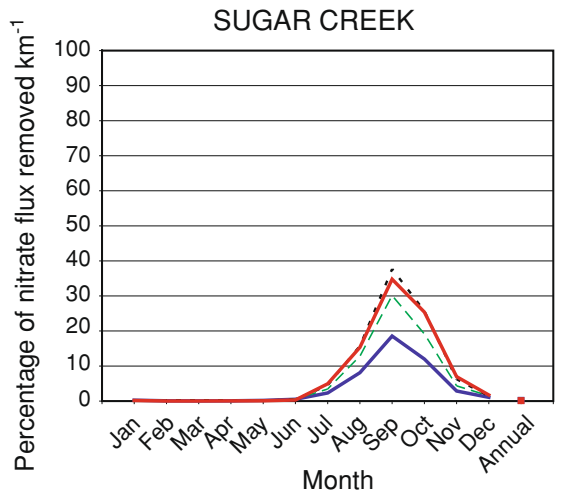

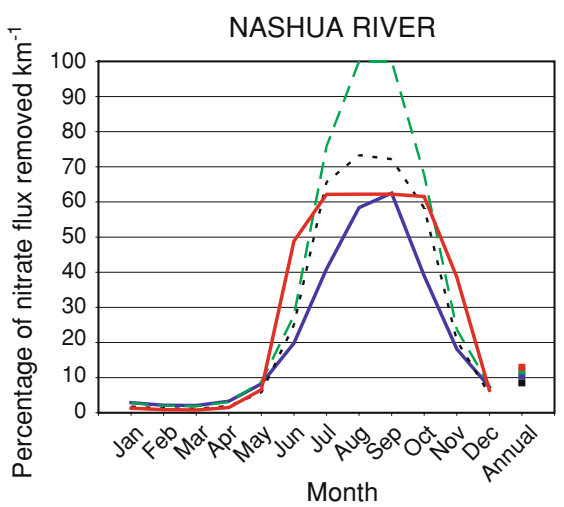

space and time between the two watersheds and among the various transport models based on different regression parameters, despite differences in the sampling and measurement techniques used by the investigators and the spatial and temporal properties of the measurements. These patterns reflect general similarities in the estimated coefficients among the different regression equations (Table 3 ). The patterns are consistent with the nonlinear inverse relation of the reaction rate constant to water-column nitrate concentration and discharge, and the reciprocal effects of water velocity on the fraction of nitrate removed that are accounted for in the river network model. The spatial and temporal patterns in the relative removal rates are also generally similar to those predicted for the reaction rate constant $k$ (Eq. 3), the fraction of the nitrate mass removed per unit of water travel time. 
Overall, we find that in-stream nitrate removal by denitrification becomes appreciably less efficient during months when nitrate concentrations and discharges are high. This result is indicated by the large seasonal variations in the monthly nitrate removal percentages (Fig. 5) that span more than an order of magnitude in both the Sugar Creek and Nashua watersheds. The median nitrate removal percentages per kilometer of channel are relatively low $(<1-$ $20 \% \mathrm{~km}^{-1}$ of the monthly stream nitrate flux) during months of high discharge and nitrate concentration (February to June), whereas higher nitrate removal (typically from 30 to $70 \% \mathrm{~km}^{-1}$ ) is predicted during months of low discharge and concentration (August to November). The smallest range of seasonal variation in the $\%$ of nitrate removed per kilometer of channel is predicted by the LINX model (Fig. 5a), whereas the ODR predictions display the largest seasonal variations (Fig. 5c); these results are consistent with differences in their respective regression models as highlighted in the sensitivity analyses (Table 5). In addition, we find that the annual nitrate removal percentages - the $\%$ of the annual nitrate mass removed when simulated on the basis of mean annual measures of discharge, water velocity, and nitrate concentration and lateral loading to streams-is generally similar to the monthly removal percentages predicted for the high-discharge and concentration months (February-June), a pattern that is related to the discharge-weighted nature of the annual predictions.

In contrast to the order-of-magnitude seasonal variability in the monthly nitrate removal percentages, we find that stream-size related differences in these percentages (Fig. 5) are much smaller, typically differing by less than $20 \%$ units from first-order to fourth-order streams (only the ODR predictions for low flow months in the Nashua watershed are larger than this). Seasonal differences are also evident in the nitrate removal percentages by stream-size. During the high-discharge months (February-June), the nitrate removal percentages consistently decline in magnitude from headwater streams to higher order streams in both watersheds, although the overall change is substantially less than $10 \%$ units. During the low-discharge months, the removal percentages do not display any consistent pattern of change in a downstream direction.

The large seasonal variations in the nitrate removal percentages (Fig. 5), compared to the stream-size related variations, are driven by synergistic monthly changes in the hydrological and biogeochemical properties that influence denitrification, including discharge, water depth and velocity, nitrate loading to streams, and water-column nitrate concentration. For example, the low nitrate removal percentages predicted during the high-discharge months are explained by the effects of large nitrate loadings, concentrations, water depth, and water velocities (and short water travel times). In contrast to the seasonal variations, the smaller stream-size related variations are explained by the countervailing or moderating downstream effects on nitrate removal percentages of declining nitrate concentrations and increasing discharge, water depth, and velocity (and decreasing reciprocal velocity or water time of travel). The declines in nitrate concentrations in a downstream direction are related to the cumulative effects of the sequential removal of nitrate in upstream reaches. Predictions of seasonal differences in the stream-size related variations in nitrate removal percentages (Fig. 5) reflect seasonal changes in the relative importance of the downstream effects of discharge on water velocity and depth vs. the effects of nitrate loadings on in-stream nitrate removal and nitrate concentrations. Overall, the seasonal and spatial patterns in the nitrate removal percentages are generally consistent with those from recent field and modeling studies of seasonal and dischargerelated variability in stream nitrate removal (Royer et al. 2004; Smith et al. 2006; Wollheim et al. 2008b; Böhlke et al. 2008).

Differences between the two watersheds in the monthly percentages of nitrate removed per unit channel length (Fig. 5) reveal the importance of biogeochemical factors (including anthropogenic nitrate loadings, land use, and in-stream concentrations) as a major control on reach-scale denitrification and in-stream nitrate removal, as evidenced by the disproportionately lower nitrate removal efficiency in the nitrate-enriched Sugar Creek watershed as compared with that in similar months and stream sizes in the less enriched Nashua watershed. The nitrate removal efficiency is substantially lower during the high-discharge months (February-June) in the Sugar Creek watershed than predicted for the Nashua watershed during these months; generally smaller differences are predicted in the removal efficiencies of the two watersheds during months with relatively 
low discharge (August-November). During the highdischarge months, the nitrate removal percentages in the Sugar Creek watershed are less than $20 \%$ of those in the Nashua watershed, based on the USGS regression parameters (Fig. 5b) —e.g., the Nashua percentages for May range from 2 to $16 \% \mathrm{~km}^{-1}$ in the four stream-size classes, whereas comparable Sugar Creek percentages are $<1 \% \mathrm{~km}^{-1}$. By comparison, the nitrate removal percentages in the lowdischarge months in the Sugar Creek watershed are typically no smaller than a third of those in the Nashua watershed (Fig. 5b)-e.g., the Sugar Creek removal percentages for September range from 26 to $36 \% \mathrm{~km}^{-1}$ in the four stream-size classes, whereas comparable Nashua percentages range from 34 to $61 \% \mathrm{~km}^{-1}$. The magnitude of the differences in nitrate removal efficiency between the two watersheds is even more pronounced for the ODR predictions of the nitrate removal percentages (Fig. 5c). This result reflects the higher sensitivity of the ODR regression model to changes in biogeochemical factors (loadings, concentrations) and lower sensitivity to hydrological factors (water depth, discharge) compared to that for the other regression models (Table 5). We also find that the annual nitrate removal percentages for all of the field data sets (Fig. 5) follow the same patterns as those during the high-discharge months. Overall, our findings of a reduced capacity of streams to remove nitrate by denitrification in response to elevated nitrate loadings are generally consistent with recent results from a dynamic model of the Ipswich River network (Wollheim et al. 2008b) and a steady-state model of spring/ summer conditions in a Tennessee stream network based on the LINX data (Mulholland et al. 2008).

Evaluations of the sensitivity of the monthly nitrate removal percentages per kilometer to multiplicative changes in discharge and nitrate loadings and their effects on related stream properties (e.g., water velocity, nitrate concentration; Table 2; Fig. 6) provide insight into the relative importance of hydrological and biogeochemical factors on nitrate removal within the watershed streams (Fig. 5). Both discharge and nitrate loadings to streams in the Sugar Creek and Nashua river networks span approximately a 10-fold range seasonally and spatially. Therefore, the range of the multiplicative changes evaluated in the sensitivity analyses is generally representative of conditions in the case study watersheds. The sensitivity results are reported only for headwater streams in Fig. 6, but similar results were obtained for higher order streams in the networks.

The sensitivity analyses (Fig. 6) confirm the importance of biogeochemical factors, represented by nitrate loadings and stream concentrations, as major controls on nitrate removal in the watershed streams. However, the analyses also reveal the important role of hydrological factors (discharge, velocity, depth), which contribute nearly equally to seasonal and stream-size related variations in the nitrate removal percentages in the streams of each watershed, based on the USGS and LINX results. The ODR results suggest that biogeochemical factors (i.e., nitrate loadings) may play an even greater role than hydrological factors in explaining nitrate removal, consistent with the sensitivity results for the regression relations (Table 5). We also find that the magnitude of the change in the nitrate removal percentages (in absolute \% units; Fig. 6) in response to changes in either biogeochemical or hydrological factors is generally less in the nitrateenriched Sugar Creek streams, although the relative changes in the removal percentages are generally similar in both watersheds.

For Nashua streams, multiplicative changes in nitrate loadings cause a substantially larger biogeochemical response in stream nitrate removal than similar changes in discharge and related hydrological factors, according to the ODR results (Fig. 6c), whereas the hydrological response is similar to the biogeochemical response for the LINX and USGS results (Fig. 6a, b). For example, doubling the nitrate loadings lowers the \% nitrate removal per kilometer in Nashua streams during May by 30\% (from 10 to $7 \% \mathrm{~km}^{-1}$ ) versus a $25 \%$ reduction in the removal percentages in response to doubling the hydrological factors, based on the LINX models (the comparable relative reductions in the nitrate removal percentages for the ODR results are about 40 versus $20 \%$, respectively). During the low-discharge months, the biogeochemical and hydrological responses are also similar to one another, based on the USGS and LINX models (note that the relative response of the nitrate removal percentages to changes in either biogeochemical or hydrological factors during the lowdischarge months is slightly smaller than that during the high-discharge months, whereas the response in absolute \% units per kilometer during the lowdischarge months is generally larger). 
Fig. 6 Sensitivity of the median percentage of instream nitrate flux removed per kilometer of channel in headwater reaches of the Sugar Creek and Nashua River watersheds to changes in the hydrological and biochemical factors affecting denitrification, reported for the reaction rate constant regressions for the field datasets: a LINX, b USGS and $\mathbf{c}$ ODR. The field datasets include USGS

(Smith et al. 2006; Böhlke et al. 2008), LINX

(Mulholland et al. 2008, 2009), ODR (Royer et al. 2004; Opdyke et al. 2006; Opdyke and David 2007).

Table 1 describes the sensitivity methods; simulation of biogeochemical effects reflect multiplicative changes in nitrate loadings, whereas hydrological effects reflect multiplicative changes in discharge. The "base condition" simulations refer to the median percentage nitrate removal per kilometer for first-order streams in Fig. 5. Note that the sensitivity results for headwater streams are similar to those predicted for larger secondthrough fourth-order streams (a) LINX
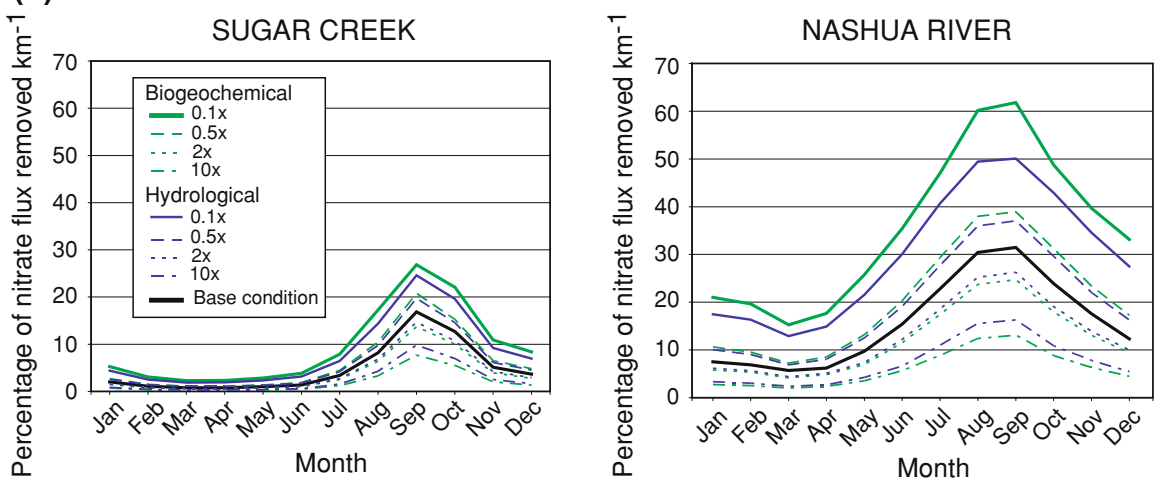

(b) USGS


(c) ODR

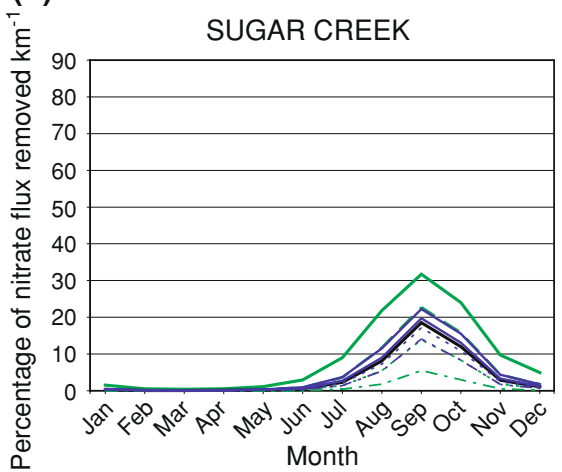

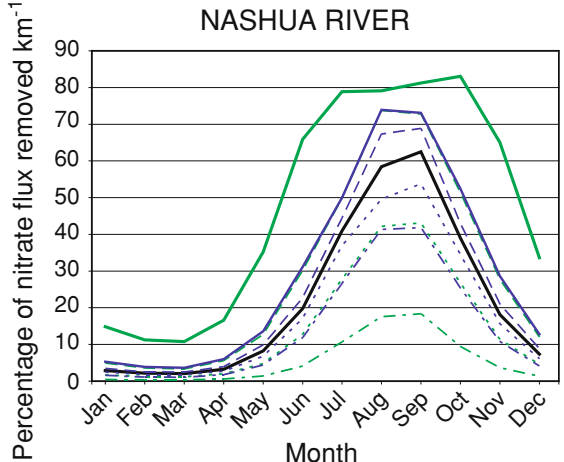

For streams in the Sugar Creek watershed, the results are similar; changes in nitrate loadings cause a larger biogeochemical response in the nitrate removal percentages according to the ODR results (Fig. 6c), whereas the hydrological response is again similar to the biogeochemical response for the USGS and LINX results (Fig 6a, b). The greater importance of the biogeochemical factors in explaining the ODR results (Fig. 6c) is consistent with the large differences in the
ODR predictions of the nitrate removal percentages between the two watersheds (Fig. 5c). On the basis of the USGS results, doubling the discharge lowers the nitrate removal percentages during high-discharge months by about $32 \%$, whereas doubling the nitrate loadings results in a reduction in the removal percentages by about $29 \%$. We also find that water depth is indicated as a more important hydrological factor than water velocity - the response of the nitrate 
removal percentages per kilometer to changes in water velocity represents about $30 \%$ of the response to hydrological factors, according to the USGS results (about $40 \%$ for the LINX results), with water depth accounting for the remainder of the response; these results are similar for the Nashua watershed.

Statistical uncertainties in the reaction rate constant regressions (Tables 3,4) contribute to uncertainties in the river network predictions of the monthly nitrate removal percentages per kilometer (Fig. 5). We evaluated the magnitude of these uncertainties in Monte Carlo analyses $(N=100)$ that account for model coefficient and residual variance errors in the reaction rate constant regression models; estimation uncertainties in monthly discharge and nitrate loadings to streams are generally small relative to those of the regression models and were not included. We find that the ratios of the standard deviation to the mean of the monthly nitrate removal percentages from the Monte Carlo simulations typically vary (i.e., interquartile range) during high-discharge months from about 1.41.5 (i.e., equivalent to a standard deviation of 140 $150 \%$ of the mean) in first-order streams and from about 2.1-2.3 in fourth-order streams, based on the LINX predictions. Comparable ratios for the USGS predictions typically vary during high-discharge months from about 0.64-0.71 (interquartile range) in first-order streams and from about 1.2-1.4 in fourthorder streams. During the low-discharge months, the ratios vary from about $1.2-1.3$ in first-order streams and from about 1.8-2.3 in fourth-order streams for LINX predictions (comparable USGS predictions are $0.45-0.53$ and $0.85-1.1$, respectively). Uncertainties in the ODR predictions are larger than those in the LINX predictions because of the much higher statistical uncertainties for the ODR regression equations (Tables 3,4). The uncertainties of the various models indicate generally greater statistical resolution of the larger seasonal variations in the nitrate removal percentages compared to that for the smaller streamsize related differences.

\section{Mass removal of nitrate by denitrification in streams}

Whereas the monthly predictions of the percentage of nitrate removed per unit channel length (Fig. 5) are typically lower during periods and locations of high nitrate flux, concentration and discharge, the predicted absolute quantities of nitrate mass removed per unit of channel length are among the largest for the same periods, locations, and nitrate conditions. For example, the median quantities of nitrate mass removal per unit channel length in high-discharge months are about an order of magnitude higher than those during lowdischarge months (e.g., 0.02 versus $0.003 \mathrm{~kg} \mathrm{~m}^{-1}$ in first-order streams of Sugar Creek, respectively, based on LINX results; the predictions are generally similar for the USGS and ODR models). Additionally, the nitrate mass removal quantities increase from headwater to fourth-order streams, and display a generally similar range of variation as that predicted to occur seasonally. The predicted increases in nitrate mass removal per unit channel length with stream size in a downstream direction are complex functions of decreasing nitrate concentration (tending to decrease $U$ and increase $V_{f}$ and $k$ ), increasing discharge (tending to decrease $k$ and water travel time), and increasing stream width (which increases the benthic surface area providing contact between water-column nitrate and biogeochemically reactive substrates). The predictions of larger nitrate mass removal in large streams than in small streams are generally consistent with the patterns of nitrate mass removal reported in the literature (Seitzinger et al. 2002; Wollheim et al. 2006, 2008b; Ensign and Doyle 2006; Mulholland et al. 2008).

We also find that larger quantities of nitrate mass are removed in nitrate-enriched streams as evidenced by monthly removal quantities that are one to two orders of magnitude higher in the first- to fourth-order streams of Sugar Creek compared to the quantities in Nashua streams-i.e., $0.002-0.4$ vs. $0.0005-$ $0.03 \mathrm{~kg} \mathrm{~m}^{-1}$, respectively. Whereas nitrate enrichment increases the magnitude of the nitrate mass removed in all seasons, enrichment has little effect on the seasonal share of the annual nitrate mass that is removed. We find that this share is similar for the two watersheds-e.g., about 60 and $13 \%$ of the annual nitrate mass that is removed is predicted to occur during the high-discharge (February-June) and lowdischarge months (August-November), respectively, in both Sugar Creek and Nashua streams, based on the LINX model estimates.

By contrast, nitrate enrichment does alter where nitrate mass removal occurs in river networks as evidenced by the significantly larger quantities of nitrate mass that are removed in higher order streams of the nitrate-enriched Sugar Creek watershed. For 
example, summing the nitrate mass removal separately by stream order, we find that fourth-order streams are predicted to account for a much larger share $(29 \%)$ of the total nitrate mass removed in all streams of the Sugar Creek watershed, compared to the share for headwater streams $(17 \%)$, based on the LINX model results. By contrast, in the less nitrateenriched Nashua watershed, fourth-order streams account for a smaller share $(16 \%)$ of the total nitrate mass removed in all streams, compared to the share for headwater streams (37\%). The larger nitrate mass removal in higher order streams of nitrate-enriched watersheds is also evidenced by a median mass removal per meter for fourth-order streams of the Sugar Creek watershed that is larger than that for headwater streams by a factor of 20 and 25 during low-discharge and high-discharge months, respectively; in the Nashua watershed, the median mass removal per meter for fourth-order streams is only 5 and 15 times larger than that for headwater streams during the same months. Overall, predictions of the increased importance of large streams as nitrate sinks under elevated nitrate loadings and stream nitrate concentrations are generally consistent with conclusions from recent river network model simulations (Mulholland et al. 2008; Wollheim et al. 2008b).

\section{Implications for the downstream fate of nitrate}

On the basis of the model simulations, we find that the delivery of nitrate to downstream waters-i.e., the percentage of the stream nitrate load that is delivered to the watershed outlet (Fig. 7; Eq. A11)-is strongly affected by the cumulative removal of nitrate in headwater and higher order streams during transport in the river networks. The delivery percentages (Fig. 7) account for the cumulative effects of denitrification and water travel times on the sequential removal of nitrate in streams along individual flow paths in river networks. These predictions display a dendritic pattern, similar to that reported for annual conditions in large river networks (Alexander et al. 2000, 2008). For example, we find that although the percentage of stream nitrate flux removed in individual headwater reaches of Sugar Creek in May is rather low (i.e., an average of about $3 \%$ based on the mean transit distance of one half of the reach length), the percentage of the nitrate flux in headwater streams that is removed during transit to the watershed outlet of Sugar Creek is about five- to seven-fold higherfrom 10 to 25\%; this corresponds to delivery percentages of from 75 to $90 \%$ (Fig. 7a). An additional $30 \%$ of the nitrate export from Sugar Creek is also potentially removed in downstream higher order reaches during transport over the more than $2,000 \mathrm{~km}$ of channel connecting to the Gulf of Mexico, based on current estimates (Alexander et al. 2008) of the mean water travel times to the Mississippi River outlet and the mean annual first-order total nitrogen rate constants for the intervening river reaches.

Furthermore, differences in the nitrate delivery percentages between the two watersheds (Fig. 7a, b) demonstrate the importance of biogeochemical factors, related to anthropogenic nitrate loadings and in-stream concentrations, as a control on cumulative in-stream nitrate removal via denitrification at the
Fig. 7 Percentages of the stream nitrate loads in May that are delivered to the outlets of the watersheds: a Sugar Creek, b Nashua River. Percentages predicted from the application of the LINX field data (Mulholland et al. 2008,2009 ) in the river network simulation model (a) SUGAR CREEK

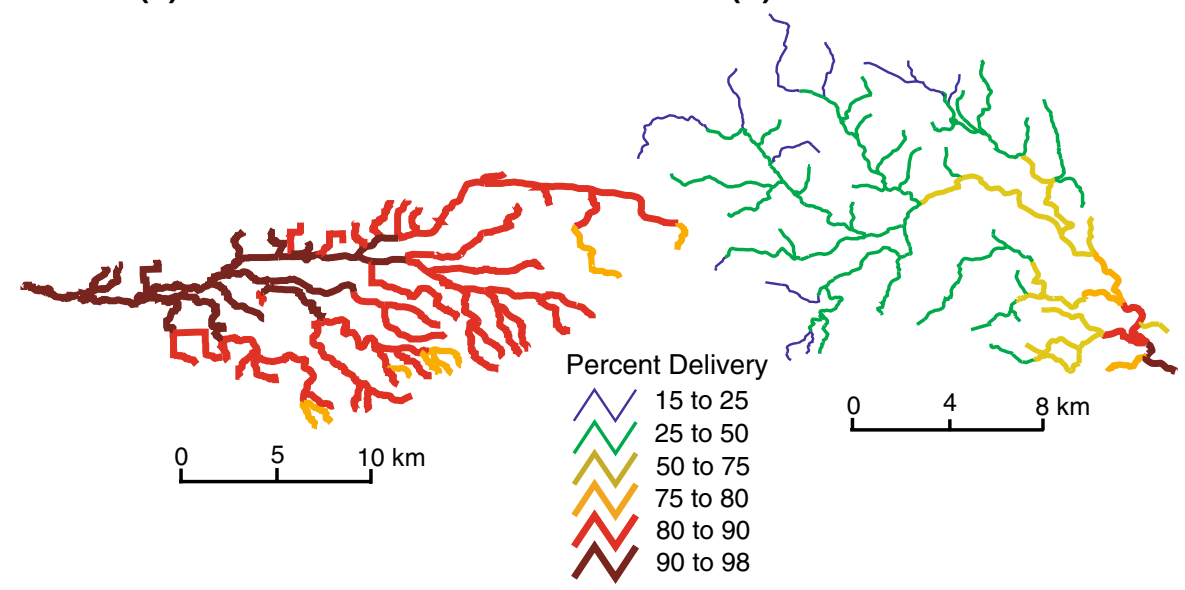


river network scale. Nitrate delivery percentages in the less nitrate-enriched Nashua watershed are substantially lower and span a much wider range (i.e., 1597\%) than those in the nitrate-enriched Sugar Creek watershed, where the percentages of in-stream nitrate flux delivered to the outlet are relatively large $(>75 \%)$ for all stream reaches in the watershed.

The nitrate delivery percentages (Fig. 7) illustrate the important role that streams of all sizes play in nitrate removal and the downstream transport of nitrogen in river networks. Information on cumulative removal is especially useful to identify critical upstream watersheds, where nitrogen management or land use change would be expected to have the most direct effect on nitrate delivery to downstream receiving waters (and presumably where management actions would entail the least costs). These critical upstream watersheds are generally associated with streams that drain catchments in which the fractions of nitrate removed by denitrification are small and the delivery to downstream waters are large (e.g., $>90 \%$; Fig. 7). The model simulations and field measurements of denitrification analyzed in this study provide key insights into the effects of biogeochemical and hydrological factors on the spatial and temporal dynamics that influence cumulative nitrate removal and delivery to downstream waters.

\section{Conclusions}

The application of a nitrate transport model to watersheds with highly contrasting land uses and nitrate loadings provides new insight into the effects of denitrification on stream nitrate removal in response to hydrological and biogeochemical rate-controlling properties. Unique to our study is the use of more than 300 field measurements of denitrification from three independent reach-scale investigations, which indicate nonlinear dependence of stream denitrification on nitrate concentration, discharge, and temperature. Despite differences in the measurements and their uncertainties, we find marked similarities in both space and time in the nonlinear denitrification regression relations and the river network predictions of nitrate removal. The general agreement in the functional relations and model predictions is encouraging, and offers multiple, independent lines of evidence that lend credibility to our river network model simulations.
The results indicate that the nitrate removal efficiency in the stream reaches of river networks, expressed as the percentage removal of the monthly in-stream nitrate flux per kilometer of channel, is substantially reduced during periods and locations with high nitrate loadings, concentrations, and discharges. Seasonal variations in the nitrate removal percentages are appreciably larger than stream-size related (stream order) variations, owing to the synergistic effects on nitrate removal of seasonal changes in biogeochemical and hydrological properties versus the countervailing effects of downstream changes in selected properties (e.g., nitrate concentration, water depth). Although these patterns are generally consistent with those reported in literature studies of the three field data sets evaluated here (Royer et al. 2004; Smith et al. 2006; Mulholland et al. 2008, 2009; Wollheim et al. 2008b; Böhlke et al. 2008), our modeling evaluations of the case study watersheds reveal new information about the relative importance of biogeochemical versus hydrological effects on nitrate removal. The findings underscore the importance of biogeochemical factors, related primarily to nitrate enrichment (loadings and stream concentrations), as major controls on nitrate removal in the watershed streams, but also suggest that hydrological factors contribute nearly equally to seasonal and stream-size related variations in the nitrate removal percentages in each watershed, with water depth indicated as a more important hydrological factor than water velocity. Overall, the results demonstrate the important biogeochemical effects of anthropogenic nitrogen sources and land use on reach-scale denitrification and nitrate removal. Of particular importance are their effects on the cumulative fractional reduction of nitrate loads in river networks during critical high-discharge periods that significantly influence downstream nitrate delivery.

The findings highlight the need for additional experimental data collection and improved connections between experimental data and large-scale watershed models to improve the accuracy of model predictions of nitrate removal by denitrification in river networks. Despite similarities in our reach-scale predictions of stream nitrate removal based on the different field measurements, the prediction uncertainties are appreciable. For example, the accuracy of the predictions of the monthly median nitrate removal percentage per kilometer varies among the models 
from a low of about $65 \%$ to more than $200 \%$ of the mean (one standard deviation) during high-discharge months. This allows reasonable separation of the major seasonal shifts in the nitrate removal percentages, but limits the ability to reliably discern differences in the removal percentages within seasons and across the range of stream sizes where the percentages display less variability. The large seasonal variations in the reaction rate constants and nitrate removal percentages, particularly those associated with the USGS and ODR field data, stress the importance of continued evaluations of dischargeand temperature-related seasonal variability in denitrification in future stream studies using multiple reach-scale experimental sampling and analytical techniques. Studies are especially needed that simultaneously expand both the spatial and temporal scales of measurement given that recent reach-scale studies have tended to emphasize either space (site-to-site differences across varied land uses; LINX) or time (seasonal and discharge differences at relatively few sites with uniform land use; USGS, ODR).

New sampling also needs to include a broader range of discharge regimes, stream sizes, ratecontrolling variables (e.g., organic matter, biotic uptake, respiration; Smith et al. 2006; Opdyke et al. 2006; Opdyke and David 2007; Mulholland et al. 2008, 2009), and aquatic environments including floodplains (Richardson et al. 2004; Wollheim et al. 2008b) and lakes and reservoirs (Harrison et al. 2008). Sampling in streams larger than those in the case study watersheds is technically challenging, but has particular importance for improving measurements of the cumulative effects of nitrogen removal in river networks. Such sampling would also improve the linkages between the experimental field data and watershed scale nutrient models (e.g., SPARROW, SWAT, THMB/IBIS; see Boyer et al. 2006). These watershed models are capable of estimating nitrogen removal in moderate- to large-sized rivers using mass balance techniques, but have highly imprecise spatial and temporal descriptions of denitrification and its effects on nitrogen transport. As these models are increasingly applied at smaller scales (e.g., NHD), opportunities exist to improve their accuracy by exploring methods for incorporating existing (e.g., Alexander et al. 2007) and future experimental field measurements of denitrification and associated ratecontrolling relations into the models.
Acknowledgments We thank G. Schwarz, D. Robertson, D. Saad, R. Moore, and D. Wolock of the US Geological Survey (USGS) for providing hydrologic and nutrient data for the National Hydrologic Data river network. Special thanks to Robert Runkel (USGS), David Wolock (USGS), William Parton (Colorado State University), and two anonymous reviewers for their comments on prior versions of the manuscript. This paper is a product of a workshop on Denitrification Modeling Across Terrestrial, Freshwater, and Marine Systems, held November 28-30, 2006, at the Institute of Ecosystem Studies, Millbrook, NY, with support from the Denitrification Research Coordination Network of the National Science Foundation (award DEB0443439) and the Northeastern States Research Cooperative (Grant \# 02-CA-11242343-105). The research was also supported by the USGS National Water-Quality Assessment Program, and received partial support from grants NSF-DEB0614282 and NSF-OCE-9726921 (Plum Island LTER).

Open Access This article is distributed under the terms of the Creative Commons Attribution Noncommercial License which permits any noncommercial use, distribution, and reproduction in any medium, provided the original author(s) and source are credited.

\section{Appendix}

\section{A1. Predicting reaction rate constants for Sugar Creek and Nashua streams}

Predictions of the reaction rate constant ( $k$ in the transport simulation model in Eq. 1) were determined for each reach in the two river networks by separately applying the five regression equations associated with the three experimental data sets. For each stream reach $i$ and month $s$, we apply the reaction rate constant regression Eq. 3 [for LINX, USGS and ODR] to the river network data, such that

$k_{i, s}=b_{0} C_{i, s}^{b 1} H_{i, s}^{b 2}\left[\sin \left(2 \pi T_{i, s}\right)\right]^{b 3}\left[\cos \left(2 \pi T_{i, s}\right)\right]^{b 4} c^{t}$

where $c^{t}$ is the log re-transformation bias correction factor specific to each reaction rate constant regression; the nitrate concentration in reach $i$ is based on the sum of the nitrate flux from the upstream reach $j$ and lateral nitrate loadings in reach $i$ (Eq. 1; see "Lateral loadings of nitrate to streams") and the discharge in reach $i$ (see "Stream hydrological estimates"), such that

$C_{i, s}=\frac{F_{j, s}+F_{i, s}^{I}}{Q_{i, s}}$. 
Note that the concentration in Eq. (A2) provides a conservative estimate of the water-column nitrate concentration (i.e., overestimate), given that nitrate removal via assimilation in aquatic plants and organisms is not included; this may cause an underestimation of the nitrate removal percentage by denitrification in the model simulations (see "Lateral loadings of nitrate to streams"). Reaction rate constants are determined from the river network application of Eq. 5 and the benthic areal rate regression Eq. 4 [for USGS and ODR only], such that

$$
k_{i, s}=\frac{b_{0} C_{i, s}^{b_{1}^{\prime}} H_{i, s}^{b_{2}^{\prime}}\left[\sin \left(2 \pi T_{i, s}\right)\right]^{b_{3}^{\prime}}\left[\cos \left(2 \pi T_{i, s}\right)\right]^{b_{4}^{\prime}} c^{c^{\prime}}}{C_{i, s} d_{i, s}},
$$

where $c^{t^{\prime}}$ is the log re-transformation bias correction factor specific to each benthic areal rate regression equation.

Note that the use of predictions from the LINX regressions (Eq. A1) in the nitrate transport model (Eq. 1) assumes that the spatial dependence of the reaction rate constants on nitrate concentration and water depth provides a reliable description of the temporal dependence on these variables. Our analysis provides a limited evaluation of this assumption, given that the ODR regressions reflect the seasonal dependence of denitrification on nitrate concentration and temperature, while the USGS regressions reflect seasonal dependence of denitrification on discharge and concentration (although not temperature). We assume that the temperature-related seasonal variability in the ODR model developed for conditions in the Illinois streams applies equally well to Nashua streams. The supporting hydrological and waterquality data and related methods required to apply the transport simulation model are presented in "Stream hydrological estimates" and "Lateral loadings of nitrate to streams".

\section{A2. Stream hydrological estimates}

The mean monthly discharge in Eq. A2 is determined for each reach within the Sugar Creek and Nashua watersheds by computing the downstream accumulation of the estimated annual and monthly runoff associated with the incremental drainage of each reach in the NHD river network for the period
1982-2001 (Sugar Creek) and 1995-2001 (Nashua). Runoff data were estimated following the approach of Krug et al. (1989; D. Wolock, USGS, personal communication) and were obtained from the US Geological Survey WaterWatch web site (http://water. usgs.gov/waterwatch/?m=romap\&r=us\&w=real $\% 2 \mathrm{C}$ map). The mean monthly water velocity (units = $\mathrm{m} \mathrm{s}^{-1}$ ) is determined for each reach from mean monthly and annual discharge, based on a previously published empirical analyses of stream time-of-travel data in relation to the peak concentration (Jobson 1996), and is calculated as

$v_{i, s}=0.02+0.051 D_{a}^{0.821}\left(\frac{Q_{i, s}}{Q_{a}}\right)^{-0.465} \frac{Q_{i, s}}{D_{a}}$

where $Q$ is the discharge $\left(\mathrm{m}^{3} \mathrm{~s}^{-1}\right)$ for the specified month, $Q_{a}$ is the long-term period of record mean discharge (e.g., 1982-2001; units $=\mathrm{m}^{3} \mathrm{~s}^{-1}$ ), and $D_{a}$ is the dimensionless drainage area defined as

$D_{a}=\frac{D^{1.25} \sqrt{g}}{Q_{a}}$

where $D$ is the drainage area $\left(\mathrm{m}^{2}\right)$ and $g$ is the acceleration of gravity $\left(\mathrm{m} \mathrm{s}^{-2}\right)$. The Jobson (1996) Eqs. (A4-A5) are based on data from more than 980 sub-reaches on 90 US rivers $(\mathrm{N} \cong 900)$, and are used to describe both at-a-station (temporal) and downstream (spatial) variability in water velocity in the river network simulations. Applying the Jobson equations in the simulations, the resulting exponents of the water velocity-discharge relation are approximately 0.48 for the at-a-station changes and 0.18 for the downstream changes; this compares with the commonly cited exponents of 0.34 and 0.10 , respectively, based on empirical measurements $(N=114)$ reported for nine major US rivers (Leopold and Maddock 1953). Also, channel width is generally more responsive to downstream changes in discharge than to at-a-station changes in discharge, based on the width-discharge relations (width $=$ discharge ${ }^{X}$, where $x=0.42$ vs. 0.12 , respectively). The mean water depth associated with each discharge value is calculated based on measurements for US rivers $(N=114)$ reported by Leopold and Maddock 1953 and empirically estimated in Alexander et al. (2000); the at-a-station and downstream exponents of the depth-discharge relation are both 0.397 . In addition to the monthly statistics (e.g., Eqs. A4-A5), mean 
annual values of discharge, velocity, and depth were also computed to support parallel estimates of mean annual nitrate load and nitrate removal in streams for comparison with the monthly estimates.

\section{A3. Lateral loadings of nitrate to streams}

The lateral loadings of nitrate from the incremental drainage area of each reach, $F_{i, s}^{I}$ (Eq. 1), are estimated as the product of a representative basin-wide, multiyear, monthly time series record of nitrate yield $\left(Y_{s}\right.$; mass per unit drainage area per time) and the incremental drainage area of each reach $\left(D_{i}^{I}\right)$, such that $F_{i, s}^{I}=Y_{s} D_{i}^{I}$.

The time series of monthly nitrate yields is derived from nearby stream monitoring records of nitrate concentrations and daily discharges for each of the two watersheds. The records are for the stream monitoring sites at Sugar Creek at Milford, Illinois (drainage area $=1,155 \mathrm{~km}^{2}$ ) for the period 19822001 (located downstream of the outlet of the watershed used for the simulations) and Stillwater River near Sterling, MA (drainage area $=75 \mathrm{~km}^{2}$ ) for the period 1995-2001 (located in an adjacent watershed to the south of the North Nashua watershed). These records provide a generally representative description of the approximate magnitude and monthly variability of the ground and surface water inflows to streams in the modeled river networks; the inflows reflect nitrate inputs from anthropogenic and natural sources. Although the cumulative effects of in-stream removal processes (i.e., biotic assimilation, storage, denitrification) require that the actual loadings to stream reaches are higher than indicated by these monitoring records, adjustment for these effects is beyond the scope of this study. Therefore, the input nitrate loads, stream nitrate concentrations, and denitrification rates in our simulations are not intended to identically match those of the case study watersheds, but rather to illustrate contrasts. For example, doubling the assumed lateral nitrate loadings in Eq. A6 would lower predictions of the monthly nitrate removal percentages per kilometer of stream channel (Fig. 6) by $14-30 \%$, based on the LINX and USGS simulations. A 10 -fold increase in the assumed lateral nitrate loadings lowers the nitrate removal percentages by $42-70 \%$. Note that the effects of these different nitrate loading assumptions on the monthly removal percentages are assessed as part of the sensitivity evaluations of biogeochemical factors (i.e., nitrate loadings; Table 2; Fig. 6). We assume that the lateral nitrate yields (Eq. A6) are homogenous across all catchments within each watershed; thus, the analysis does not account for spatial variability in watershed land use. In general, an assumption of constant land use (and lateral nitrate loadings) is more realistic for Sugar Creek, which is dominated by cornsoybean cultivation, than for the Nashua watershed, which has more heterogeneous land use.

We use the monitoring data at the Sugar Creek (Milford) and Stillwater River monitoring sites to estimate monthly nitrate yields (Eq. A6) for the periods of the nitrate and discharge records, based on statistical rating curve estimation methods (Schwarz et al. 2006). Accordingly, we first model the measured stream nitrate flux according to

$$
\begin{aligned}
\ln \left(F_{m}\right)= & \beta_{0}+\beta_{1} T_{m}+\beta_{2} \ln \left(Q_{m}\right)+\beta_{3} \sin \left(2 \pi T_{m}\right) \\
& +\beta_{4} \cos \left(2 \pi T_{m}\right)+\varepsilon_{m}
\end{aligned}
$$

where $F_{m}$ is the instantaneous nitrate flux (mass time $^{-1}$; product of the instantaneous concentration and mean daily discharge) for the $m$ th observation; $T_{m}$ as described earlier is decimal time in years (the descriptor of annual linear trend in flux); $\ln$ is the natural logarithm, $Q_{m}$ is contemporaneous mean daily discharge; seasonal variability is described by trigonometric functions of decimal time; $\varepsilon_{m}$ is the model error assumed to be independently and identically distributed as a normal random variable with mean zero and standard deviation $\sigma$; and $\beta_{0}, \beta_{1}, \ldots, \beta_{4}$ are estimated log-linear regression coefficients. Model residuals were evaluated for normality and constant variance following calibration of the models.

Mean monthly estimates of nitrate yield are predicted by integrating Eq. A7 with the mean value of discharge on day $r$ across all days, $p_{\mathrm{s}}$, in each month, such that

$$
\begin{aligned}
\mathrm{Y}_{\mathrm{s}} & =\left[\sum _ { r = 1 } ^ { p _ { s } } \operatorname { e x p } \left[\beta_{0}+\beta_{1} T_{r, s}+\beta_{2} \ln \left(Q_{r, s}\right)\right.\right. \\
& \left.\left.+\beta_{3} \sin \left(2 \pi T_{r, s}\right)+\beta_{4} \cos \left(2 \pi T_{r, s}\right)\right] c_{r, s}\right] \frac{1}{D^{M}}
\end{aligned}
$$

where $c_{r, s}$ is the Duan $\log$ re-transformation bias correction factor (Schwarz et al. 2006), and $\mathrm{D}^{\mathrm{M}}$ is the 
drainage area upstream of the monitoring site. This calculation is repeated for all months in the multiyear period of the available discharge record to determine the time series of monthly yields for each basin. Annual nitrate yields are also calculated to support the estimation of annual values of stream nitrate flux and denitrification in the river network reaches. As expected based on the model predictions, the response of nitrate yield to changes in discharge is larger for the highly agricultural Sugar Creek monitoring site (discharge exponent of 1.504) compared to the highly forested and modestly urbanized watershed upstream of the Stillwater river site (coefficient of 0.934).

\section{A4. Stream nitrate removal metrics}

The monthly fraction of the nitrate removed by denitrification in stream reaches is computed as the difference between the decayed and non-decayed stream nitrate fluxes. Specifically, we calculate the monthly nitrate removal in reach $i\left(R_{i, s}^{r}\right)$ as a percentage of the total nitrate mass flux in the reach (sum of the upstream nitrate flux and lateral nitrate loadings) per unit of reach length $x_{i}$, such that

$R_{i, s}^{r}=\left[\frac{\left(\left(F_{j, s}+F_{i, s}^{I}\right)-F_{i, s}^{D}\right)}{\left(F_{j, s}+F_{i, s}^{I}\right)} 100\right] \frac{1}{x_{i}}$.

We also calculate the absolute mass quantity of nitrate removed by denitrification $\left(R_{i, s}^{M}\right)$ expressed per unit of reach length, according to

$R_{i, s}^{M}=\left[\left(F_{j, s}+F_{i, s}^{I}\right)-F_{i, s}^{D}\right] \frac{1}{x_{i}}$.

Finally, a cumulative measure of the percentage of the nitrate flux entering an upstream reach $y\left(P_{y, s}\right)$ that is delivered to the downstream end of reach $i$ the outlet of the Sugar Creek or Nashua watershedis determined as the product of the nitrate transport fractions for reach $y, i$ and all intervening stream reaches (with $z$ denoting this collection of reaches), such that

$P_{y, s}=\left(\prod_{z} e^{\frac{-k_{z, s} A_{z, s} x_{z}}{Q Q_{z} s}}\right) 100$.

This provides information about the downstream fate of nitrate specific to the flow path that connects each reach in the river network to the watershed outlet. Note that for reach $y$ only one half of the reach length is applied in keeping with the model assumption that the lateral nitrate loadings to a stream travel, on average, one half the length of the reach.

\section{References}

Alexander RB, Smith RA, Schwarz GE (2000) Effect of stream channel size on the delivery of nitrogen to the Gulf of Mexico. Nature 403:758-761

Alexander RB, Boyer EW, Smith RA, Schwarz GE, Moore RB (2007) The role of headwater streams in downstream water quality. J Am Water Resour Assoc 43:41-59. doi: 10.1111/j.1752-1688.2007.00005.x

Alexander RB, Smith RA, Schwarz GE, Boyer EW, Nolan JV, Brakebill JW (2008) Differences in phosphorus and nitrogen delivery to the Gulf of Mexico from the Mississippi River basin. Environ Sci Technol 42:822-830

Andrews P, Ilieve P, Gilland K, Cooter B, Kramer B, Dewald T (2002) Moving from 1:100 K NHD to $1: 24 \mathrm{~K}$ resolution: case studies. ESRI user conference proceedings

Birgand F, Skaggs RW, Chescheir GM, Gilliam JW (2007) Nitrogen removal in streams of agricultural catchments-a literature review. Crit Rev Environ Sci Technol 37:381-487

Böhlke JK, Harvey JW, Voytek MA (2004) Reach scale isotope tracer experiment to quantify denitrification and related processes in a nitrate-rich stream, mid-continent USA. Limnol Oceanogr 49:821-838

Böhlke JK, Antweiler R, Harvey JW, Laursen A, Smith LK, Smith RL, Voytek MA (2008) Multi-scale measurements and modeling of denitrification in streams with varying flow and nitrate concentration in the upper Mississippi River basin, USA. Biogeochemistry. doi:10.1007/s10533008-9282-8

Boyer EW, Alexander RB, Parton WJ, Li C, Butterbach-Bahl K, Donner SD, Skaggs RW, Del Grosso SJ (2006) Modeling denitrification in terrestrial and aquatic ecosystems at regional scales. Ecol Appl 16:2123-2142

Cohn TA, Caulder DL, Gilroy EJ, Zynzuk LD, Summers RM (1992) The validity of a simple statistical model for estimating fluvial constituent loads: an empirical study involving nutrient loads entering Chesapeake Bay. Water Resour Res 28:2353-2363

Donner SD, Coe MT, Lenters JD, Twine TE, Foley JA (2002) Modeling the impact of hydrological changes on nitrate transport in the Mississippi river basin from 1955-1994. Global Biogeochem Cycles 16:1043. doi:10,1029/2001 GB00396

Ensign SH, Doyle MW (2006) Nutrient spiraling in streams and river networks. J Geophys Res 111:G04009. doi: 10.1029/2005JG000114

Garcia Ruiz R, Pattinson SN, Whitton BA (1998) Kinetic parameters of denitrification in a river continuum. Appl Environ Microbiol 64:2533-2538

Hall RO Jr, Tank JL, Sobota DJ, Mulholland PJ, O'Brien JM, Dodds WK, Webster JR, Valett HM, Poole GC Peterson 
BJ, Meyer JL, McDowell WH, Johnson SL, Hamilton SK, Grimm NB, Gregory SV, Dahm CN, Cooper LW, Ashkenas LR, Thomas SM, Sheibley RW, Potter JD, Niederlehner BR, Johnson L, Helton AM, Crenshaw C, Burgin AJ, Bernot MJ, Beaulieu JJ, Arango C (2009) Nitrate removal in stream ecosystems measured by ${ }^{15} \mathrm{~N}$ addition experiments: total uptake. Limnol and Oceanogr (in press)

Harrison J, Maranger R, Alexander R, Giblin A, Jacinthe P, Mayorga E, Seitzinger S, Sobota D and Wollheim W (2008) The regional and global significance of nitrogen removal in lakes and reservoirs. Biogeochemistry. doi: 10.1007/s10533-008-9272-x

Howarth RW, Billen G, Swaney D, Townsend A, Jaworski N, Lajtha K, Downing JA, Elmgren R, Caraco N, Jordan T, Berendse F, Freney J, Kudeyarov V, Murdoch P, ZhaoLiang Z (1996) Regional nitrogen budgets and riverine $N$ $\&$ P fluxes for the drainages to the North Atlantic Ocean: natural and human influences. Biogeochemistry 35:75139

Jobson HE (1996) Prediction of traveltime and longitudinal dispersion in rivers and streams. U.S. geological survey, water-resources investigations report 96-4013

Krug WR, Gebert WA, Graczyk DJ (1989) Preparation of average annual runoff map of the United States, 1951-80. U.S. geological survey open-file report 87-535

Leopold LB, Maddock T Jr. (1953) The hydraulic geometry of stream channels and some physiographic implications. U.S. geological survey professional paper 252

Mulholland PJ, Valett HM, Webster JR, Thomas SA, Cooper LW, Hamilton SK, Peterson BJ (2004) Stream denitrification and total nitrate uptake rates measured using a field ${ }^{15} \mathrm{~N}$ tracer addition approach. Limnol Oceanogr 49:809-820

Mulholland PJ, Helton AM, Poole GC, Hall RO Jr, Hamilton SK, Peterson BJ, Tank JL, Ashkenas LR, Cooper LW, Dahm CN, Dodds WK, Findlay S, Gregory SV, Grimm NB, Johnson SL, McDowell WH, Meyer JL, Valett HM, Webster JR, Arango C, Beaulieu JJ, Bernot MJ, Burgin AJ, Crenshaw C, Johnson L, Niederlehner BR, O'Brien JM, Potter JD, Sheibley RW, Sobota DJ, Thomas SM (2008) Stream denitrification across biomes and its response to anthropogenic nitrate loading. Nature 452:202-205. doi:10.1038/nature06686

Mulholland PJ, Hall RO Jr, Sobota DJ, Dodds WK, Findlay S, Grimm NB, Hamilton SK, McDowell WH, O'Brien JM, Tank JL, Ashkenas LR, Cooper LW, Dahm CN, Gregory SV, Johnson SL, Meyer JL, Peterson BJ, Poole GC, Valett HM, Webster JR, Arango C, Beaulieu JJ, Bernot MJ, Burgin AJ, Crenshaw C, Helton AM, Johnson L, Niederlehner BR, Potter JD, Sheibley RW, Thomas SM (2009) Nitrate removal in stream ecosystems measured by ${ }^{15} \mathrm{~N}$ addition experiments: denitrification. Limnol and Oceanogr (in press)

Newbold JD, Elwood JW, O'Neill RV, Van Winkle W (1981) Measuring nutrient spiraling in streams. Can J Fish Aquat Sci 38:860-863

Opdyke MR, David MB (2007) Response of sediment denitrification rates to environmental variables in streams heavily impacted by agriculture. J Freshwat Ecol 22: 371-382

Opdyke MR, David MB, Rhoads BL (2006) The influence of geomorphological variability in channel characteristics on sediment denitrification in agricultural streams. J Environ Qual 35:2103-2112

Peterson BJ, Wollheim WM, Mulholland PJ, Webster JR, Meyer JL, Tank JL, Marti E, Bowden WB, Valett HM, Hershey AE, McDowell WH, Dodds WK, Hamilton SK, Gregory S, Morrall DD (2001) Control of nitrogen export from watersheds by headwater streams. Science 292:86-90

Pina-Ochoa E, Alvarez-Cobelas M (2006) Denitrification in aquatic environments: a cross-system analysis. Biogeochemistry 81:111-130

Richardson WB, Strauss EA, Bartsch LA, Monroe EM, Cavanaugh JC, Vingum L, Soballe DM (2004) Denitrification in the Upper Mississippi river: rates, controls, and contribution to nitrate flux. Can J Fish Aquat Sci 61:1102-1112

Royer TV, Tank JL, David MB (2004) The transport and fate of nitrate in headwater, agricultural streams in Illinois. J Environ Qual 33:1296-1304

Runkel RL (2007) Toward a transport-based analysis of nutrient spiraling and uptake in streams. Limnol Oceanogr Methods 5:50-62

Schwarz GE, Hoos AB, Alexander RB, Smith RA (2006) The SPARROW surface water-quality model: theory, application and user documentation. U.S. geological survey techniques and methods report, book 6, chap. B3

Seitzinger S, Styles RV, Boyer EW, Alexander RB, Billen G, Howarth RW, Mayer B, Van Breemen N (2002) Nitrogen retention in rivers: model development and application to watersheds in the Eastern U.S. Biogeochemistry 57: 199-237

Smith LK, Voytek MA, Böhlke JK, Harvey J (2006) Denitrification in nitrate-rich streams: application of $\mathrm{N}_{2}: \mathrm{Ar}$ and ${ }^{15} \mathrm{~N}$ tracer methods in intact cores. Ecol Appl 16:21912207

Stream Solute Workshop (1990) Concepts and methods for assessing solute dynamics in stream ecosystems. J North Am Benthol Soc 9:95-119

Wollheim WM, Voorosmarty CJ, Peterson BJ, Seitzinger SP, Hopkinson CS (2006) Relationship between river size and nutrient removal. Geophys Res Lett 33. doi: 10.1029/2006GL025845

Wollheim WM, Vorosmarty CJ, Bouwman AF, Green PA, Harrison J, Linder E, Peterson BJ, Seitzinger S, Syvitski JPM (2008a) Global N removal by freshwater aquatic systems: a spatially distributed, within-basin approach. Global Biogeochem Cycles 22:GB2026. doi:2010.1029/2007 GB002963

Wollheim WM, Peterson BJ, Vorosmarty CJ, Hopkinson C, Thomas SA (2008b) Dynamics of $\mathrm{N}$ removal over annual time scales in a suburban river network. J Geophys ResBiogeosciences. doi:10.1029/2007JG000660

U.S. Geological Survey (2000) National hydrography dataset. http://nhd.usgs.gov/chapter1/chp1_data_users_guide.pdf 